\title{
Antihypertensive Effect of Ethanolic Extract from Acanthopanax sessiliflorus Fruits and Quality Control of Active Compounds
}

\author{
In Ho Jung, ${ }^{1}$ Sung Eun Kim, ${ }^{2}$ Yeong-Geun Lee, ${ }^{3}$ Dae Hyun Kim, ${ }^{2}$ Haneul Kim, ${ }^{2}$ \\ Geum-Soog Kim, ${ }^{4}$ Nam-In Baek, ${ }^{3}$ and Dae Young Lee $\mathbb{\circledR}^{4}$ \\ ${ }^{1}$ Department of Life and Nanopharmaceutical Science, College of Pharmacy, Kyung Hee University, Seoul 02447, Republic of Korea \\ ${ }^{2}$ Daehwa Pharmaceutical Co. Ltd., Seongnam 13488, Republic of Korea \\ ${ }^{3}$ Department of Oriental Medicine Biotechnology, Kyung Hee University, Yongin 17104, Republic of Korea \\ ${ }^{4}$ Department of Herbal Crop Research, National Institute of Horticultural and Herbal Science, RDA, \\ Eumseong 27709, Republic of Korea
}

Correspondence should be addressed to Dae Young Lee; dylee0809@gmail.com

Received 1 September 2017; Revised 11 January 2018; Accepted 27 February 2018; Published 23 April 2018

Academic Editor: Eric E. Kelley

Copyright (c) 2018 In Ho Jung et al. This is an open access article distributed under the Creative Commons Attribution License, which permits unrestricted use, distribution, and reproduction in any medium, provided the original work is properly cited.

\begin{abstract}
Acanthopanax sessiliflorus (Rupr. \& Maxim.) Seem., which belongs to the Araliaceae family, mainly inhabits Korea, China, and Japan. Traditionally, Acanthopanax species have been used as treatment for several diseases such as diabetes, tumors, and rheumatoid arthritis. Especially, its fruits have many biological functions including antitumor, immunostimulating, antithrombosis, and antiplatelet activities. Recently, the extract of A. sessiliflorus fruit has been reported to have antithrombotic and antiplatelet activities related to the alleviation of hypertension. Therefore, we investigated the antihypertensive effect of ethanolic extract from A. sessiliflorus fruits (DHP1501) through in vivo, ex vivo, and in vitro studies. In this study, DHP1501 demonstrated free radical scavenging capacity, enhanced endothelial nitric oxide (NO) production, and inhibited angiotensinconverting enzyme (ACE) activity in spontaneously hypertensive rats (SHRs), resulting in the improvement of vascular relaxation and decrease in blood pressure in the hypertensive animal model. These results suggest that A. sessiliflorus fruit extract may be a promising functional material for the prevention and treatment of hypertension. Furthermore, this study demonstrated the utility of MS-based active compounds for the quality control of DHP1501.
\end{abstract}

\section{Introduction}

Hypertension, or the state of high blood pressure, is defined as above $140 \mathrm{mmHg}$ systolic blood pressure (SBP) and $90 \mathrm{mmHg}$ diastolic blood pressure (DBP). It is one of the most significant causes of mortality worldwide since elevated blood pressure is considered to be the leading risk factor for coronary artery disease and its complications such as heart failure, stroke, renal disease, and diabetes [1]. Hypertension is also regarded as the major risk factor for disability-adjusted life years worldwide according to the Global Burden of Disease study $[1,2]$. The World Health Organization predicts that 1.5 billion people will suffer from hypertension by 2025 and that more than 7 million deaths yearly are likely to be caused by hypertension [3]. Owing to the global impact of hypertension, many studies have investigated antihypertensive medications and new therapeutic alternatives $[4,5]$. There are various types of antihypertensive medications-such as angiotensin-converting enzyme (ACE) inhibitors, beta-blockers, and calcium channel blockers-owing to the many physiological mechanisms of blood pressure control including cardiac output, peripheral vascular resistance, and circulating blood volume $[6,7]$. These antihypertensive drugs are extensively used for the treatment of hypertension and related cardiovascular diseases, but they are reported to have adverse side effects as well [5, 6]. According to Hom et al. [8], ACE inhibitor, angiotensin receptor blockers, and calcium channel blockers cause upper respiratory track abstraction and angioedema in adults and children. Calcium channel blockers contribute to the 
development and progression of cancer through the inhibition of vascular cell growth and angiogenic growth factors induced by the increase of apoptosis [9]. Other side effects of antihypertensive drugs, including dyspnea, cough, hair loss, headache, edema, and flushes, have been reported as well $[10,11]$. Thus, an alternative therapy such as herbal drugs is preferred because natural herbal products using medicinal plants are considered to have fewer side effects [5]. Recently, medicinal plants have been reported to be effective in hypertension and empirically used as antihypertensive agents $[12,13]$. The antihypertensive effects of plants are attributed to their antioxidant properties because oxidative stress is considered a risk factor in hypertension and cardiovascular diseases $[14,15]$. Oxidant stress is caused by the imbalance between the generation of free radicals such as reactive oxygen and nitrogen species and antioxidant defense mechanisms [16]. Reactive oxygen species (ROS) produced in all vascular cells including endothelial, smooth muscle cells, and phagocytic cells play an important role in the pathophysiology of hypertension by causing vascular damage and reducing the production of nitric oxide (NO), which maintains the vascular tone [16, 17]. As such, excessive ROS is observed in patients with essential hypertension [18], with a close relationship between blood pressure and some parameters associated with oxidative stress reported [19]. Thus, antioxidants can promote the reduction of high blood pressure by trapping free radicals [16].

Acanthopanax sessiliflorus (Rupr. \& Maxim.) Seem., which belongs to the Araliaceae family, is reported to contain antioxidants [20]. It is widely found in the Far Eastern region of Russia and Northeast Asian countries including Korea, Japan, and China, and its stem and root are traditionally used for the treatment of rheumatoid arthritis, inflammation, and diabetes in oriental medicine [21-23]. In China, its fruits are used to develop various food therapy products because they are proven to be effective in cardiovascular and cerebrovascular diseases without toxicity. As such, Yang et al. [24] reported that the ethanolic extract of $A$. sessiliflorus fruits (DHP1501) had significant antithrombotic and antiplatelet activities. The activation of platelets occurs in hypertension, and platelet aggregation is involved in the development of vascular complications related to hypertension [25-27]. Interestingly, $A$. sessiliflorus fruits contain a high amount of secotriterpenoid glycosides, which are a member of the triterpenoid family, in addition to lignans and phenolics. Among these, chiisanoside, $22 \alpha$-hydrochiisanoside, and their aglycone (Figure 1) are the major compounds of $A$. sessiliflorus fruits, showing effects on the anti-inflammation, antioxidant, and ACE inhibition using HUVECs (human umbilical vein endothelial cells) $[21,28-31]$. Based on these results, we hypothesized that the extract of $A$. sessiliflorus fruits has potential antihypertensive effects. Therefore, we investigated our hypothesis in this study.

\section{Materials and Methods}

2.1. Preparation of Ethanolic Extract of A. sessiliflorus Fruits. A. sessiliflorus fruits were cultivated in Jeongseon, Gangwon Province, South Korea. A voucher specimen (NIHHS1501) was deposited at the Herbarium of the Department of Herbal Crop Research, National Institute of Horticultural and Herbal Science, Rural Development Administration, Eumseong, South Korea. The fruits of $A$. sessiliflorus were extracted with $50 \%$ aqueous fermented ethanol under reflux $\left(70^{\circ} \mathrm{C}\right)$ for $6 \mathrm{~h}$ and extracted for a second time with $50 \%$ aqueous fermented ethanol under reflux $\left(70^{\circ} \mathrm{C}\right)$ for $3 \mathrm{~h}$. The extract was then filtered through a $5 \mu \mathrm{m}$ filter. The supernatant was vacuumconcentrated under reduced pressure to attain 10-20 brix materials. Then, it was sterilized at $80-90^{\circ} \mathrm{C}$ for $1 \mathrm{~h}$. Finally, the ethanolic extract of $A$. sessiliflorus fruits (referred to as DHP1501) was freeze-dried by freeze dryer under reduced pressure $\left(-30^{\circ} \mathrm{C}, 100 \mathrm{mTorr}\right)$ for $24 \mathrm{~h}$. To establish the bulk-scale production of DHP1501, we optimized the manufacturing process based on experiment scale (Figure 2).

2.2. Preparation of Sample and Standard Solutions for UPLCQTOF/MS. Standard stock solutions of $22 \alpha$-hydrochiisanoside (1), chiisanoside (2), 22 $\alpha$-hydrochiisanogenin (3), and chiisanogenin (4) were prepared by dissolving $1.00 \mathrm{mg}$ each in $1 \mathrm{~mL} 70 \%$ methanol to yield a concentration of $1.00 \mathrm{mg} /$ $\mathrm{mL}$ and were kept at $4^{\circ} \mathrm{C}$. The standard stock solutions (1-4) were diluted with methanol to obtain calibration solutions with ranges of $0.5-10,1-10,0.5-15$, and $0.5-20 \mathrm{mg} / \mathrm{mL}$, respectively. $1.00 \mathrm{~g}$ of DHP1501 was accurately weighed and dissolved in fixed volumes $(10 \mathrm{~mL})$ of methanol, filtered through a $0.20 \mathrm{~mm}$ filter paper, and refrigerated at $4^{\circ} \mathrm{C}$.

2.3. Analysis of Active Compounds Using UPLC-QTOF/MS. UPLC was performed using a Waters ACQUITY H-Class UPLC (Waters Corp.) with an ACQUITY BEH C18 column $(2.1 \times 100 \mathrm{~mm}, 1.7 \mu \mathrm{m})$. The mobile phases consisted of water (A) with $0.1 \%$ formic acid $(v / v)$ and acetonitrile (B) with $0.1 \%$ formic acid $(v / v)$. The elution gradient was as follows: 0-4 min, B 10-30\%; 4-15 min, B 30-60\%; $15-16$ min, B 60-100\%; and $16-19 \mathrm{~min}, \mathrm{~B} 100-10 \%$. The flow rate was $0.45 \mathrm{~mL} / \mathrm{min}$, and the injection volume was $2 \mu \mathrm{l}$ for each run. Next, HR-MS analysis was performed using Waters Xevo G2-S QTOF MS (Waters Corp.) operating in negative ion mode. The mass spectrometers performed alternating high- and low-energy scans known as $\mathrm{MS}^{\mathrm{E}}$ acquisition mode. Accurate mass measurements were obtained by means of an automated calibration delivery system containing Leucine enkephalin, $m / z 554.262$ (ESI neg. mode), as internal reference. Optimal operating parameters were set as shown in Table 1 [32].

\subsection{In Vitro Study}

2.4.1. Cell Culture. Human umbilical vein endothelial cells (HUVECs) were purchased from American Type Culture Collection (ATCC) and cultured at the Roswell Park Memorial Institute (RPMI) in 1640 medium (HyClone; GE Healthcare Life Sciences, UT, USA) with 10\% FBS (HyClone; GE Healthcare Life Sciences) in humidified incubator with 5\% $\mathrm{CO}_{2}$ and $37^{\circ} \mathrm{C}$.

2.4.2. Cell Viability Assay. Various concentrations (from 0.2 to $1000 \mu \mathrm{g} / \mathrm{mL}$ ) of DHP1501 were added to HUVECs seeded in a 96 -well plate at a density of $5.0 \times 10^{4}$ cells/ 


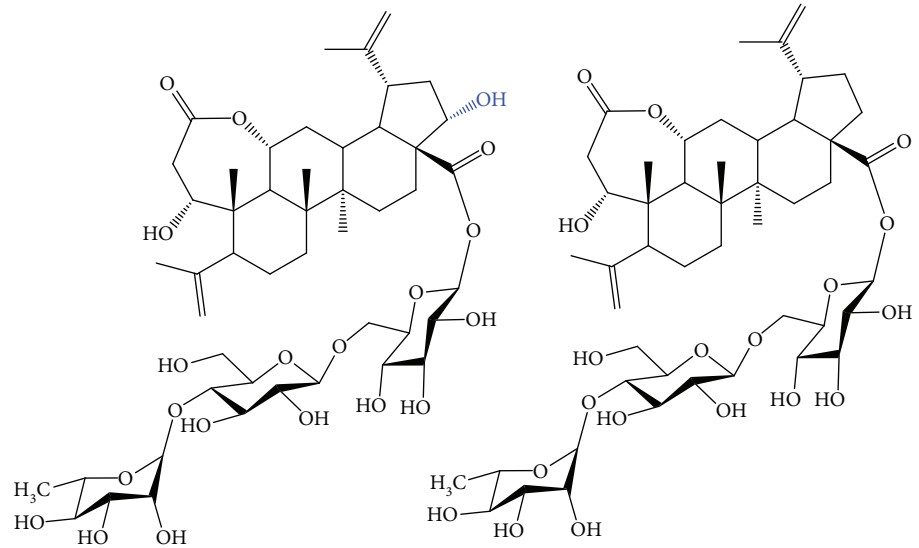

$22 \alpha$-hydroxychiisanoside (1)
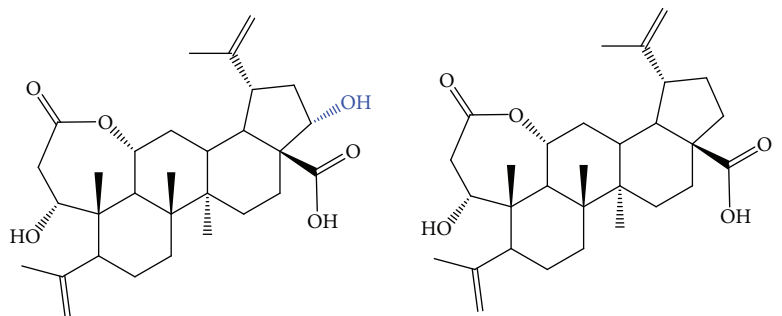

Figure 1: Structure of active compounds of $A$. sessiliflorus fruits.
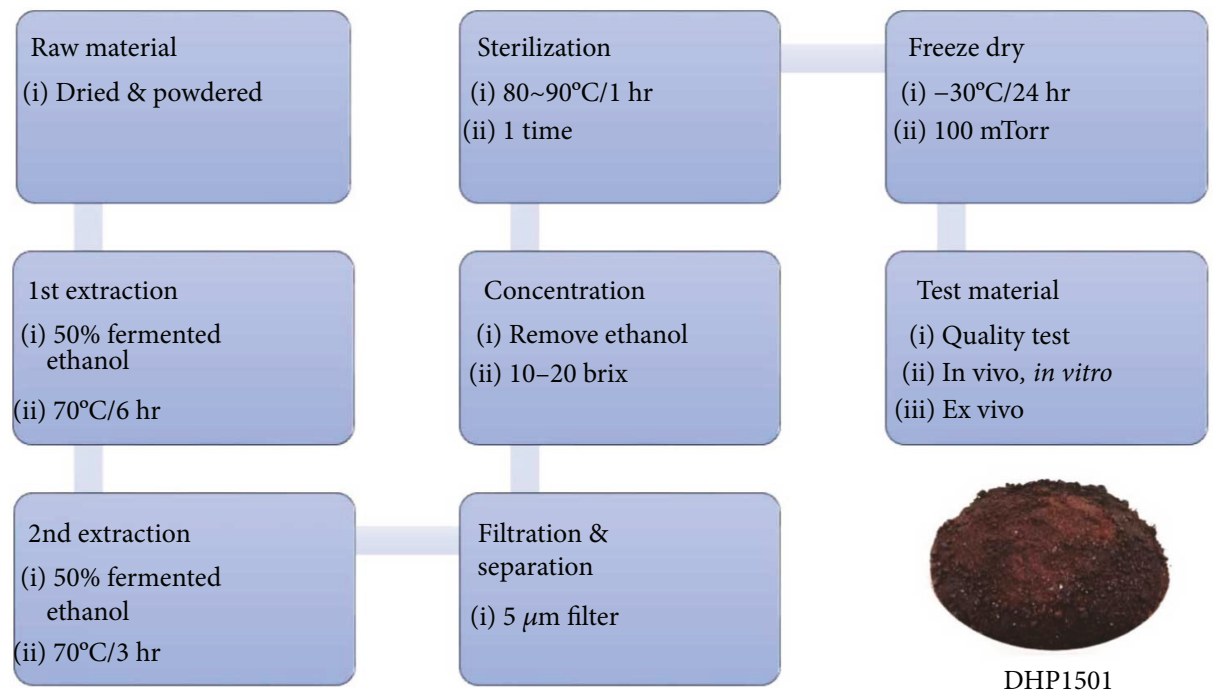

FIGURE 2: Manufacturing process for the production of DHP1501 powder.

TABLE 1: Optimal conditions for the QTOF/MS analysis of DHP1501 powder ${ }^{\mathrm{a}}$.

\begin{tabular}{lc}
\hline Optimal Q-TOF/MS condition & \\
\hline Ion source & ESI negative mode \\
Source temp. \& desolvation temp. & $120^{\circ} \mathrm{C} / 550^{\circ} \mathrm{C}$ \\
Cone gas flow \& desolvation gas flow & $30 \mathrm{~L} / \mathrm{h} / 800 \mathrm{~L} / \mathrm{h}$ \\
Capillary volt \& cone volt & $3 \mathrm{k} / 40 \mathrm{~V}$ \\
Mass range $(m / z)$ & 50 to 1.000 \\
Collision energy range & 4 to $45 \mathrm{eV}$ \\
\hline
\end{tabular}

${ }^{a}$ Table 1 is reproduced from Lee et al. [32].

$\mathrm{mL}$ and then incubated in a humidified incubator with 5\% $\mathrm{CO}_{2}$ and $37^{\circ} \mathrm{C}$ for $24 \mathrm{~h}$. Cell viability was measured by performing 3-(4,5-dimethylthiazol-2-yl)-2,5-diphenyltetrazolium bromide (MTT, Sigma-Aldrich, St. Louis, MO, USA) assay. In brief, $20 \mu \mathrm{L}$ of $5 \mathrm{mg} / \mathrm{mL}$ MTT was added, and further incubation was done for $4 \mathrm{~h}$. The supernatant of each well was then replaced with $200 \mu \mathrm{L}$ of dimethylsulfoxide (DMSO, Sigma-Aldrich) to dissolve the formed formazan crystals. The absorbance $(\mathrm{Ab})$ was determined at $595 \mathrm{~nm}$ with microplate reader (Spark 10M, TECAN, Männedorf, Switzerland). 0.5\% DMSO was used as a vehicle control with $100 \%$ viability, and percent cell survival was calculated as follows: $\%$ of cell survival $=[(\mathrm{Ab}$ of treated group - Ab of blank group)/(Ab of vehicle control - Ab of blank group) $] \times 100$.

2.4.3. Intracellular NO Measurement. The production of NO in HUVECs was measured using diaminofluoresceinFM diacetate (DAF-FM/DA, Sigma-Aldrich) assay. Briefly, the cells seeded in a 96-well black plate at a density of $2 \times 10^{4}$ cells/well were pretreated with DHP1501 (2, 20, or $200 \mu \mathrm{g} /$ $\mathrm{mL}$ ) for $90 \mathrm{~min}$ before incubation in $5 \mu \mathrm{M}$ DAF-FM/DA for $1 \mathrm{~h}$ at $37^{\circ} \mathrm{C}$. $0.5 \%$ DMSO was used as a vehicle control, with the relative levels of intracellular NO determined from the fluorescence intensity of DAF-FM at excitation of $486 \mathrm{~nm}$ 
and emission of $520 \mathrm{~nm}$ using fluorescence microplate reader (Spark 10M, TECAN).

2.4.4. Electron Passaging Ability Determinations. The electron passaging abilities of DHP1501 were measured using 2,2diphenyl-1-picrylhydrazyl (DPPH), 2,2' -azino-di-(3-ethylbenzthiazoline sulfonic acid) (ABTS), and oxygen radical absorption capacity (ORAC) assays. The DPPH radical (DPPH•) scavenging capacity assay, a decolorization assay, measures the capacity of antioxidants to react directly with DPPH radicals - which are stable organic nitrogen-centered free radicals whose dark purple color disappears when reduced to nonradical form by antioxidants-by monitoring absorbance at $517 \mathrm{~nm} .5 \mu \mathrm{L}$ of DHP1501 at final concentrations of $125,250,500$, and $1000 \mu \mathrm{g} / \mathrm{mL}$ was added to $95 \mu \mathrm{L}$ of $0.3 \mathrm{mM}$ DPPH solution and then incubated in the dark at $37^{\circ} \mathrm{C}$. The negative control was prepared with the solvent used to dissolve DHP1501. The absorbance (Ab) was determined at $517 \mathrm{~nm}$ with microplate reader (Spark 10M, TECAN), and the radical scavenging activity was calculated as a percentage using the following equation: DPPH radical scavenging activity $(\%)=[1-(\mathrm{Ab}$ of treated group $/ \mathrm{Ab}$ of negative control) $] \times 100$. The total antioxidant capacity was determined using the colorimetric 6-hydroxy-2,5,7,8-tetramethylchroman-2-carboxylic acid (Trolox)-equivalent antioxidant capacity assay kit (Cayman Chemical, Ann Arbor, USA) according to the manufacturer's protocol. This assay is based on the ability of DHP1501 to inhibit the oxidation of $\mathrm{ABTS}^{\circledR}$ when incubated with peroxidase (metmyoglobin) and hydrogen peroxide [33]. The negative control was prepared with antioxidant assay buffer, solvent of DHP1501, instead of DHP1501 in the same manner, and color development was measured using microplate reader at $750 \mathrm{~nm}$. Radical scavenging activity was calculated as a percentage using the following equation: ABTS radical scavenging activity $(\%)=[1-(\mathrm{Ab}$ of treated group/Ab of negative control) $] \times 100$. The ORAC assay is based on the scavenging of peroxyl radicals generated by AAPH $\left(2,2^{\prime}\right.$-axobis-2-methylpropanimidamide, dihydrochloride), which prevents the degradation of the fluorescein probe. ORAC antioxidant assay (Zen-Bio, Research Triangle Park, NC, USA) was performed based on the manufacturer's instructions. The reaction was performed in the wells of a microtiter plate containing DHP1501 $(0.01,0.1$, or $1 \mathrm{mg} / \mathrm{mL})$ to be tested and Trolox standard. Fluorescence was kinetically recorded every minute for $30 \mathrm{~min}$ using fluorescence microplate reader (excitation $485 \mathrm{~nm}$; emission $530 \mathrm{~nm}$ ). Areas under the fluorescence decay curve (AUC) were calculated using the following equation: $\mathrm{AUC}=0.5+(\mathrm{f} 1 / \mathrm{f} 0)+(\mathrm{f} 2 / \mathrm{f} 0)+\cdots+0.5 \times(\mathrm{f} 31 / \mathrm{f} 0)$ (f0 is normalized fluorescence at $0 \mathrm{~min}$ ). The concentration of antioxidant in DHP1501 in proportion to the fluorescence intensity was assessed by comparing the net AUC to that of Trolox, a water-soluble vitamin $\mathrm{E}$ analog used as calibration standard $(6.25,12.5,25,50$, and $100 \mu \mathrm{M})$. The net AUC is determined by subtracting the AUC for no compound addition from the other AUC values. The results were expressed as $\mu \mathrm{M}$ Trolox equivalents (TE) by the Trolox calibration standard.
2.4.5. Antioxidant Activity Determinations through ROS Measurement. The antioxidant properties of DHP1501 was measured by CellROX and DCF-DA assay. Generation of ROS was measured by using CellROX ${ }^{\mathrm{TM}}$ Deep Red Reagent (Thermo Fisher scientific) and cell-permeant $2^{\prime}, 7^{\prime}$-dichlorodihydrofluorescein diacetate $\left(\mathrm{H}_{2} \mathrm{DCFDA}\right)$ (Thermo Fisher scientific). HUVECs were seeded in a 96-well plate at a density of $5.0 \times 10^{4} \mathrm{cells} / \mathrm{mL}$ and then incubated in a humidified incubator with $5 \% \mathrm{CO}_{2}$ and $37^{\circ} \mathrm{C}$ for $48 \mathrm{~h}$. Thereafter, HUVECs were incubated under conditions of serum starvation for $4 \mathrm{~h}$. After cell starvation, for CellROX assay, HUVECs were treated with the various concentrations (from $1,10,50,100$, and $200 \mu \mathrm{g} / \mathrm{mL}$ ) of DHP1501 with $1 \mathrm{mM} \mathrm{H}_{2} \mathrm{O}_{2}$ and then incubated in a humidified incubator with $5 \% \mathrm{CO}_{2}$ and $37^{\circ} \mathrm{C}$ for $2 \mathrm{~h}$. The cells were treated with CellROX Deep Red Reagent for $30 \mathrm{~min}$ at $37^{\circ} \mathrm{C}$ following the manufacturer's references. After washing three times with PBS, the fluorescence was obtained by using fluorescence microplate reader (ex./em. 640/665, Spark 10M, TECAN). For DCF-DA assay, HUVECs were treated with the various concentrations (from $10,50,100$, and $200 \mu \mathrm{g} / \mathrm{mL}$ ) of DHP1501 with $500 \mu \mathrm{M} \mathrm{H}_{2} \mathrm{O}_{2}$ and then incubated in a humidified incubator with $5 \% \mathrm{CO}_{2}$ and $37^{\circ} \mathrm{C}$ for $3 \mathrm{~h}$. Thereafter, the cells were treated with $25 \mu \mathrm{M}$ DCF-DA for $30 \mathrm{~min}$ at room temperature. After washing three times with HBSS, the fluorescence was detected by using fluorescence microplate reader (ex./em. 485/535, Spark $10 \mathrm{M}, \mathrm{TECAN})$.

\subsection{Ex Vivo Study}

2.5.1. Preparation of Porcine Coronary Artery Rings. Porcine heart was obtained from the MK micropig (Scrofa domestica) provided by MEDIKINETICS (Gyeonggi-Do, Korea) and immediately immersed in cold normal saline. The coronary artery was dissected free from the surrounding myocardium and cleaned of any adherent fat and connective tissue. The artery was cut into rings with a diameter of $3 \mathrm{~mm}$. The rings were suspended horizontally between two parallel stainless steel hooks for the measurement of isometric tension in organ bath containing Krebs solution $(\mathrm{NaCl} 118 \mathrm{mM}, \mathrm{KCl}$ $4.7 \mathrm{mM}, \mathrm{MgSO}_{4} 1.1 \mathrm{mM}, \mathrm{KH}_{2} \mathrm{PO}_{4} 1.2 \mathrm{mM}, \mathrm{CaCl}_{2} 1.5 \mathrm{mM}$, $\mathrm{NaHCO}_{3} 25 \mathrm{mM}$, and glucose $10 \mathrm{mM}$ ) and bubbled with a mixture of $95 \% \mathrm{O}_{2}$ and $5 \% \mathrm{CO}_{2}$. The temperature was maintained at $37^{\circ} \mathrm{C}$ throughout the experiment. The isometric tension generated by the coronary artery was measured using a force-displacement transducer (Hugo Sachs, Germany) and recorded with grass physiography (Hugo Sachs). In some rings, the endothelium was removed deliberately by rubbing the luminal surface gently with a wet cotton swab, and the absence or presence of endothelial cells was confirmed by the absence or presence of relaxation to the endotheliumdependent vasodilator bradykinin $(300 \mathrm{nM})$ at $10 \mathrm{~min}$ after the rings were progressively contracted with concentrations of thromboxane A2 mimetic U46619 (from 1 to $60 \mathrm{nM}$ ) up to $80 \%$ of the maximum contraction.

2.5.2. Relaxing Effect of DHP1501 on Precontracted Coronary Artery Rings. Coronary artery rings $(n=5)$ were contracted with U46619, and various concentrations of 
DHP1501 (from 0.001 to $1 \mathrm{mg} / \mathrm{mL}$ ) were added when the U46619-induced contraction stabilized. Ginkgo biloba leaf extract (from 0.01 to $1 \mathrm{mg} / \mathrm{mL}$ ) and $0.1 \%$ DMSO were used as positive control and negative control, respectively. Dose response curves in intact and endothelium-free rings were constructed, and concentrations of DHP1501 responsible for $50 \%$ of the relaxation $\left(\mathrm{EC}_{50}\right)$ were determined.

\subsection{In Vivo Study}

2.6.1. Animals. A total of 50 male spontaneously hypertensive rats (SHRs) and 10 Wistar-Kyoto rats (WKY) (aged 6 weeks) each weighing $180 \pm 20 \mathrm{~g}$ were procured from a commercial breeder (Saeronbio, Inc., Gyeonggi-Do, Korea). We obtained institutional review board (IRB) approval for this study from the Korea Animal Medical Science Institute (KAMSI) (15-KE-216). The rats were housed under controlled environmental conditions ( $12 \mathrm{~h}$ light/dark cycle, temperature of approximately $23 \pm 3^{\circ} \mathrm{C}$, and humidity of $55 \pm 15 \%$ ) with food and water made available ad libitum throughout the experiments. Male Wistar-Kyoto rats were used as normal control (WKY), and SHRs were randomly divided into five groups ( $n=10$ in each group) according to body weight: (1) SHR (saline as the vehicle); (2) SHR-captopril 100 (a 4week daily course of oral captopril at a dose of $100 \mathrm{mg} / \mathrm{kg}$; (3) SHR-DHP1501 200 (a 4-week daily course of DHP1501 at a dose of $200 \mathrm{mg} / \mathrm{kg}$, p.o.); (4) SHR-DHP1501 400 (a 4week daily course of DHP1501 at a dose of $400 \mathrm{mg} / \mathrm{kg}$, p.o.); and (5) SHR-DHP1501 600 (a 4-week daily course of DHP1501 at a dose of $600 \mathrm{mg} / \mathrm{kg}$, p.o.).

2.6.2. Blood Pressure Measurement. Systolic and diastolic blood pressures (SBP and DBP) were measured using noninvasive and invasive methods before and after oral administration of DHP1501. They were measured once weekly using a computerized tail-cuff plethysmograph (BP-2000; Visitech Systems, Apex, NC, USA), the noninvasive blood pressure measurement method. At the end of the experimental period, they were measured using MP36 (Biopac Systems Inc., USA), the invasive blood pressure measurement method, after carotid artery cannulation with PE20 tubes. Six measurements were obtained and averaged for each rats.

2.6.3. Concentrations of Renin and Angiotensin I-Converting Enzyme (ACE). The rats were anesthetized using pentobarbital sodium, and the blood samples were collected in a vacutainer tube containing clot activator from the inferior vena cava. The samples were kept at room temperature for 15-20 min and centrifuged at $3000 \mathrm{rpm}$ for $10 \mathrm{~min}$ to obtain the serum. The serum was aliquoted and stored in an ultra-low temperature freezer $\left(-70^{\circ} \mathrm{C}\right)$ for the analysis of ACE concentration. Concentrations of ACE and renin were determined by ELISA kits based on the manufacturer's instructions (Rat REN (Renin) ELISA kit, Elabscience Biotechnology Co. Ltd., WuHan, China; Rat ACE ELISA kit, Elabscience Biotechnology) and expressed in $\mathrm{ng} / \mathrm{mL}$.

2.7. Statistical Analysis. The statistical analysis was conducted with one-way analysis of variance (ANOVA) and Kruskal-Wallis test using the Prism 5.03 (GraphPad Software
Inc., San Diego, CA, USA). One-way analysis of variance (ANOVA) was followed by the Student-Newman-Keuls test for multiple comparisons. The significance level for all analyses was set a priori at $p \leq 0.05$, and all values were expressed as the mean \pm standard deviation (SD).

\section{Results}

3.1. Identification of Standard Compounds in DHP1501. Standard compounds (1-4) were isolated and purified from the fruits of $A$. sessiliflorus by a series of chromatography procedures in our laboratory, and their structures were elucidated by a comparison of spectroscopic data (MS, ${ }^{1} \mathrm{H}-\mathrm{NMR}$, and $\left.{ }^{13} \mathrm{C}-\mathrm{NMR}\right)$ with the literature data: $22 \alpha$-hydrochiisanoside, chiisanoside, $22 \alpha$-hydrochiisanogenin, and chiisanogenin $[34,35]$. The purity of the isolated compounds was determined to be more than $99 \%$ by the normalization of the peak areas detected by UPLC analysis. Since UPLC-QTOF/MS has been proven to be a suitable tool for the identification of the four compounds, the separation of constituents in DHP1501 was performed by UPLC-QTOF/MS in a negative ion mode. Figure 3 shows a typical total ion chromatogram (TIC) of the identified compounds with mass detection.

3.2. Quantitative Analysis of DHP1501 by UPLC-QTOF/MS. Linear calibration curves were obtained for four compounds at different concentration levels. The characteristics of the calibration plots are summarized in Table 2. As seen in the table, the four compounds show excellent correlation coefficients. Detector counts (relative peak area) were linearly dependent on sample concentration over the range of $0.5-$ $1 \mu \mathrm{g} / \mathrm{mL}$ for $1,1-10 \mu \mathrm{g} / \mathrm{mL}$ for $2,0.5-15 \mathrm{mg} / \mathrm{mL}$ for 3 , and $0.5-20 \mathrm{mg} / \mathrm{mL}$ for 4 . The LODs of $22 \alpha$-hydrochiisanoside, chiisanoside, $22 \alpha$-hydrochiisanogenin, and chiisanogenin were $0.002,0.002,0.003$, and $0.009 \mathrm{ppm}$, respectively. The LOQs of $22 \alpha$-hydrochiisanoside, chiisanoside, $22 \alpha$-hydrochiisanogenin, and chiisanogenin were determined to be $0.006,0.006,0.009$, and $0.009 \mathrm{ppm}$, respectively, by UPLC-QTOF/MS in a negative ion mode. The amount of $22 \alpha$-hydrochiisanoside, chiisanoside, $22 \alpha$-hydrochiisanogenin, and chiisanogenin in the DHP1501 obtained using validation methods (Table 2) was $0.69,1.47,1.65$, and $2.71 \mathrm{mg} / \mathrm{g}$, respectively.

3.3. Evaluation of Cell Cytotoxicity of DHP1501. The in vitro cytotoxicity of DHP1501 was determined in HUVECs using MTT assay. Cell viability was $96.70 \pm 6.30,103.20 \pm 1.55$, $93.08 \pm 1.06,100.22 \pm 7.95,13.85 \pm 0.36$, or $18.69 \pm 0.49 \%$ at concentration of $0.2,2,20,200,500$, or $1000 \mu \mathrm{g} / \mathrm{mL}$, respectively (Figure 4). DHP1501 at concentrations ranging from 0.2 to $200 \mu \mathrm{g} / \mathrm{mL}$ did not exhibit toxicity on HUVECs, but 500 or $1000 \mu \mathrm{g} / \mathrm{mL}$ of DHP1501 showed cytotoxicity.

3.4. Effects of DHP1501 on NO Production in HUVECs. We investigated whether DHP1501 affects endothelial NO generation. When the DAF-FM fluorescence intensity of vehicle control was set as $100 \%$, the fluorescence intensity was $127.54 \pm 14.10,141.47 \pm 8.16$, or 167.54 $\pm 8.41 \%$ in 2,20 , or $200 \mu \mathrm{g} / \mathrm{mL}$, respectively (Figure 5). DHP1501 at the tested concentrations facilitated the 


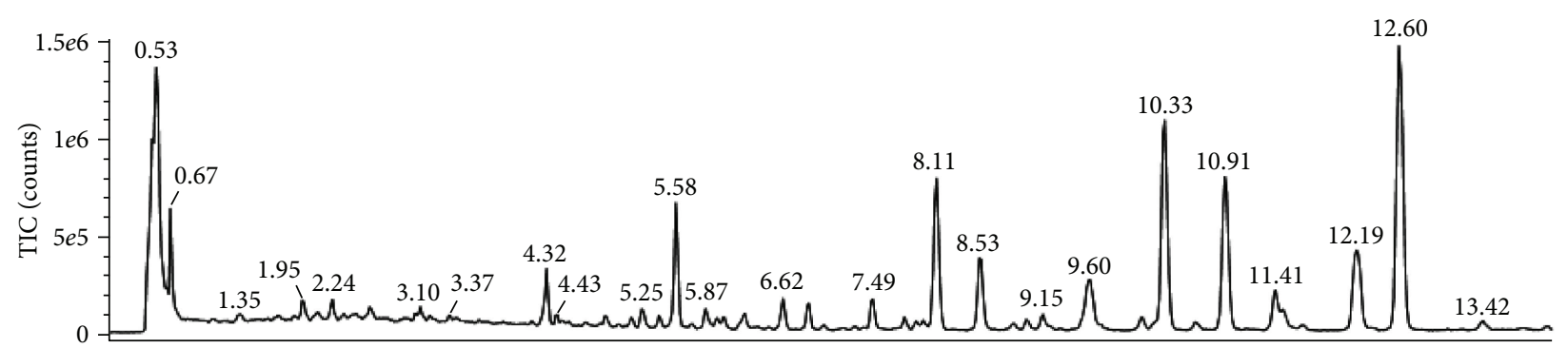

(a)

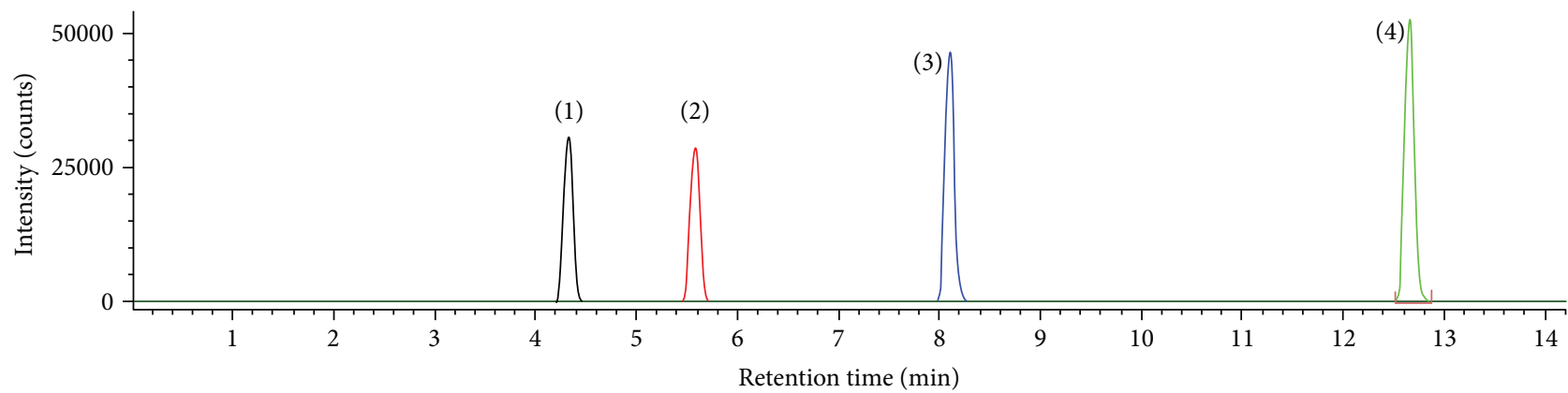

(b)
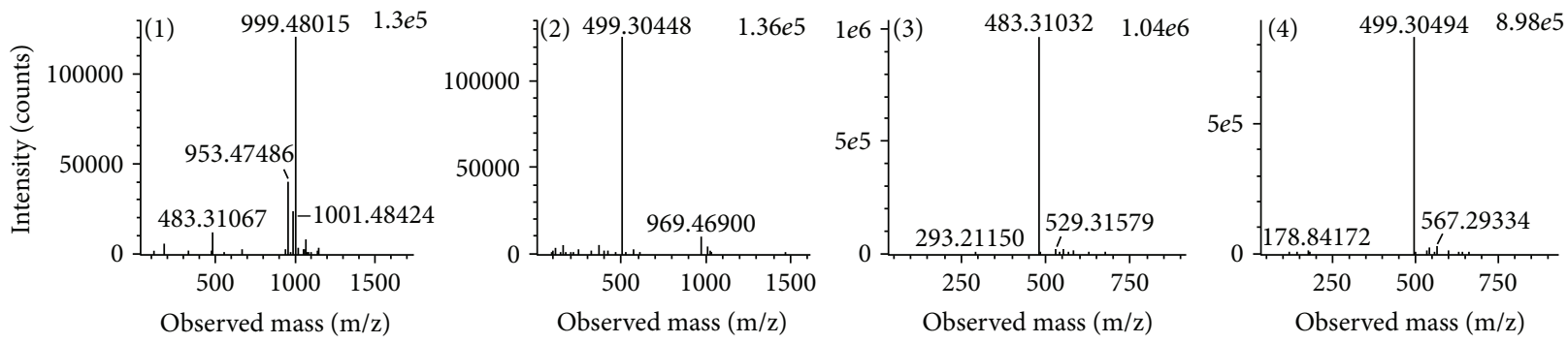

(c)

FIGURE 3: TIC of DHP1501 (a), four standard analytes (b) by UPLC-QTOF/MS in a negative ion mode by selected ion monitoring, and representative QTOF/MS chromatograms (c) for $22 \alpha$-hydrochiisanoside (1), chiisanoside (2), 22 $\alpha$-hydrochiisanogenin (3), and chiisanogenin (4).

TABLE 2: Linear regression data and contents of the validated method for the investigated compounds (1-4) in DHP1501 ${ }^{\mathrm{a}}$.

\begin{tabular}{lccccccc}
\hline Compounds & $\mathrm{Rt}^{\mathrm{b}}(\mathrm{min})$ & Calibration curve $^{\mathrm{c}}$ & $R^{2}$ & Line arrangement $(\mu \mathrm{g} / \mathrm{mL})$ & $\mathrm{LOD}^{\mathrm{d}}(\mathrm{ppm})$ & $\mathrm{LOQ}^{\mathrm{e}}(\mathrm{ppm})$ & $\mathrm{Amount}^{(\mathrm{mg} / \mathrm{g})}$ \\
\hline 1 & 4.33 & $y=765.07 x+150.61$ & 0.995 & $0.5-10$ & 0.002 & 0.006 & 0.69 \\
2 & 5.59 & $y=744.66 x+352.97$ & 0.993 & $1-10$ & 0.002 & 0.006 & 1.47 \\
3 & 8.11 & $y=2567 x+1764.10$ & 0.995 & $0.5-15$ & 0.003 & 0.009 & 1.65 \\
4 & 12.66 & $y=3119 x+2417.80$ & 0.993 & $0.5-20$ & 0.009 & 0.009 & 2.71 \\
\hline
\end{tabular}

${ }^{\mathrm{a}}$ Mean values of samples $(n=3) .{ }^{\mathrm{b}}$ Rt: retention time. ${ }^{\mathrm{c}} y$ : logarithmic value of peak area; $x$ : logarithmic value of amount injected. ${ }^{\mathrm{d}}$ LOD: limit of detection. ${ }^{\mathrm{e}}$ LOQ: limit of quantification.

endothelial NO production in a dose-dependent, significant manner $\left(\mathrm{F}_{3,23}=43.94, p<0.05\right)$.

3.5. Electron Passaging Abilities of DHP1501. The electron passaging properties of DHP1501 were determined by DPPH, ABTS, and ORAC assays. As shown in Figure 6, DHP1501 exhibited the scavenging activity of DPPH, ABTS, and peroxyl radicals. The DPPH radical scavenging activity of DHP1501 was $10.31 \pm 2.41,19.27 \pm 0.95,35.35 \pm 0.80$, or $59.22 \pm 2.17$ in $125,250,500$, or $1000 \mu \mathrm{g} / \mathrm{mL}$, respectively (Figure 6(a)). The ABTS radical scavenging activity of
DHP1501 was $0.08 \pm 0.17,8.32 \pm 1.87$, or $43.88 \pm 2.93 \%$ in 10,100 , or $1000 \mu \mathrm{g} / \mathrm{mL}$, respectively (Figure $6(\mathrm{~b})$ ). When the peroxyl radical scavenging activity was expressed as $\mu \mathrm{M}$ Trolox equivalents (TE), DHP1501 was $11.36 \pm 10.89$, $190.44 \pm 47.36$, or $614.02 \pm 22.82 \mu \mathrm{M} \mathrm{TE}$ in 10,100 , or $1000 \mu \mathrm{g} / \mathrm{mL}$, respectively (Figures 6(c) and 6(d)).

3.6. Antioxdant Activity of DHP1501 through ROS Measurement. The antioxidant properties of DHP1501 were determined by CellROX and MitoSOX assays. As shown in Figure 7(a), in CellROX assay, an increase of fluorescence 


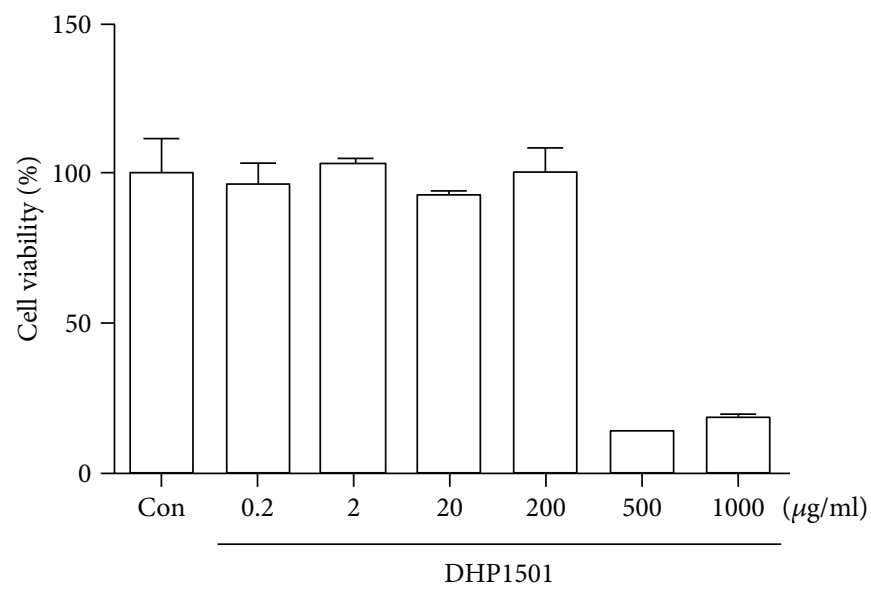

FIGURE 4: Cell viability of DHP1501. Cell viability was expressed as percentage versus vehicle control (100\%), and values were expressed as the mean \pm standard deviation (SD).

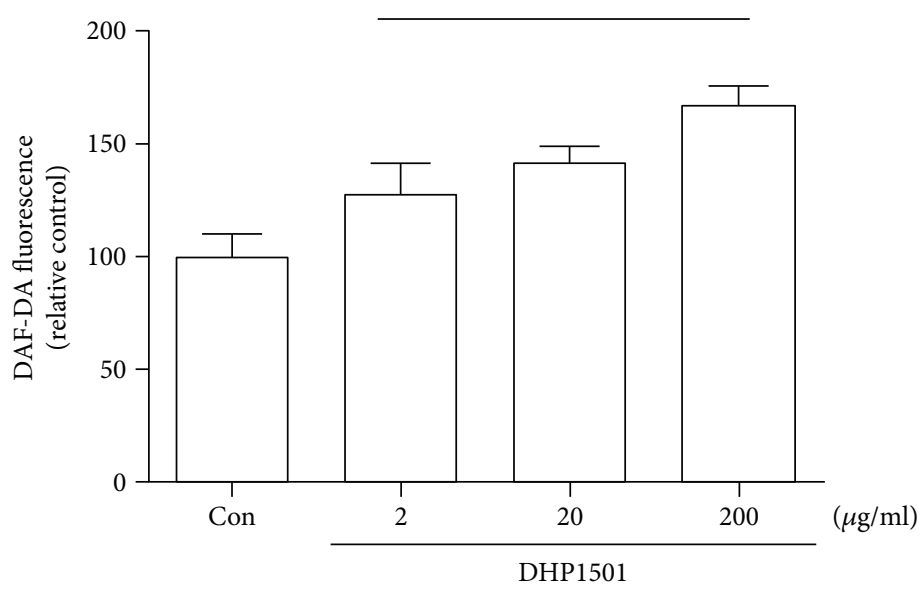

FIGURE 5: NO production effects of DHP1501 on HUVECs. NO generation was measured by using DAF-DA assay. HUVECs were treated with DHP1501 at concentrations ranging from $0.2 \mu \mathrm{g} / \mathrm{mL}$ to $200 \mu \mathrm{g} / \mathrm{mL}$, or the same volume of vehicle (Con, $0.5 \%$ DMSO in distilled water). Data represent the mean $\pm \operatorname{SD}\left(n=6\right.$ /group) $\left({ }^{*} p<0.05\right.$, versus the vehicle-treated controls).

intensity was observed in the $\mathrm{H}_{2} \mathrm{O}_{2}$-treated group (181.3 \pm 19.17 ), which was significantly reversed by the treatment of $200 \mu \mathrm{g} / \mathrm{mL}$ of DHP1501 $(143.8 \pm 23.56)$ and Vitamin C $(139.6 \pm 16.37)$, as positive control $\left(\mathrm{F}_{7,32}=9.88, p<0.05\right)$. As shown in Figure 7(b) in DCF-DA assay, an increase of fluorescence intensity was observed in the $\mathrm{H}_{2} \mathrm{O}_{2}$-treated group $(350.1 \pm 46.60)$, which was significantly reversed by the treatment of DHP1501 $(261.6 \pm 42.46)$ and Vitamin C $(261.7 \pm 18.39)\left(\mathrm{F}_{6,35}=31.88, p<0.05\right)$. It shows that the treatment of DHP1501 suppressed the $\mathrm{H}_{2} \mathrm{O}_{2}$-induced accumulation of ROS in HUVECs.

3.7. Effects of DHP1501 on Vasorelaxation. DHP1501 was determined for the potency of concentration-dependent relaxations of porcine coronary artery rings (Figure 8). The $\mathrm{EC}_{50}$ value of the vasorelaxing effect on endothelium-intact coronary artery rings was $0.26 \pm 0.03 \mathrm{mg} / \mathrm{mL}$ or 0.29 $\pm 0.06 \mathrm{mg} / \mathrm{mL}$ in DHP1501 or Ginkgo biloba leaf extract as the positive control, respectively. The $\mathrm{EC}_{50}$ value for the endothelium-free coronary artery rings was 0.16 $\pm 0.03 \mathrm{mg} / \mathrm{mL}$ in DHP1501, but no vasorelaxing effect by ginkgo extract was observed. Specifically, DHP1501 reduced contractile responses to thromboxane mimetic U46619 in porcine coronary rings in a dose-dependent manner regardless of endothelium.

3.8. Effects of DHP1501 on Blood Pressure in SHRs. At the beginning of the experiment, SBP and DBP were significantly higher in the SHR groups than in the WKY. SBP and DBP in SHR were gradually increased during the experiment period and were the highest at 4 weeks $(197.5 \pm 13.0$ and 148.5 $\pm 8.0 \mathrm{mmHg}$ in SBP and DBP, resp.). On the other hand, SBP and DBP in SHR-captopril as positive control were significantly reduced after 1 week of treatment and were maintained at the lowest levels during the experiment period compared with SHR (SBP: $\mathrm{F}_{5,54}=26.68$; DBP: $\mathrm{F}_{5,54}=21.42$ ). Oral administration of DHP1501 reduced SBP and DBP in a dose-dependent manner at 1 week and significantly 


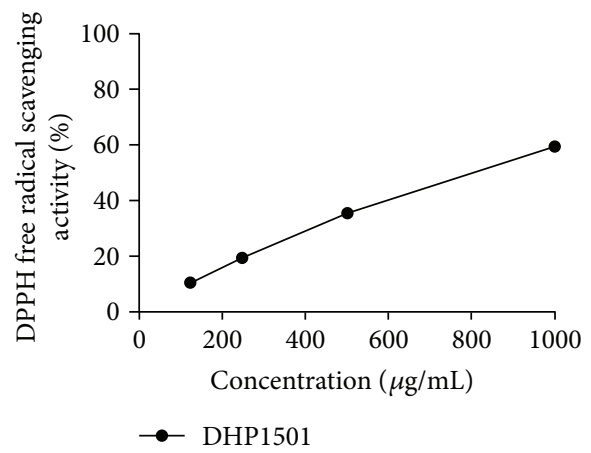

(a)

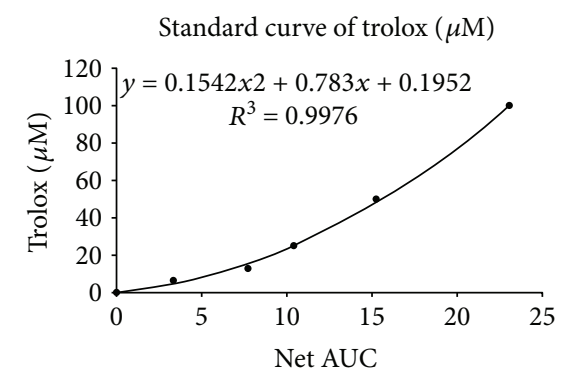

(c)

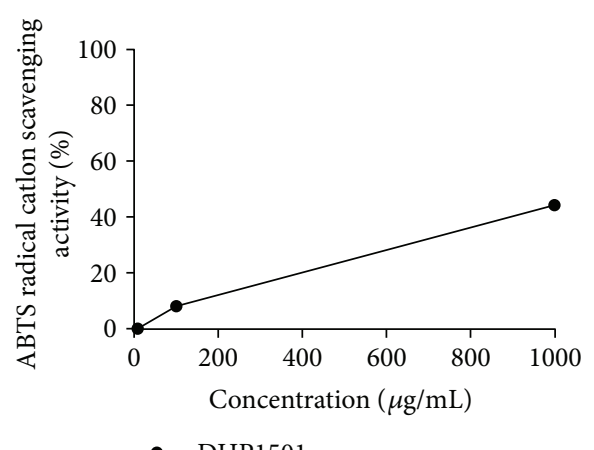

(b)

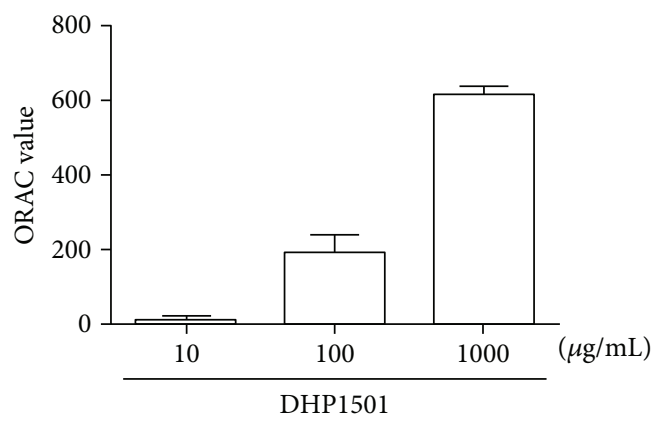

(d)

FIgURE 6: The electron passaging properties of DHP1501. (a) DPPH radical scavenging activity. (b) ABTS radical scavenging activity measured by ORAC assay. (c) Trolox standard curve (or decay curve of fluorescence). (d) ORAC values expressed as TE.

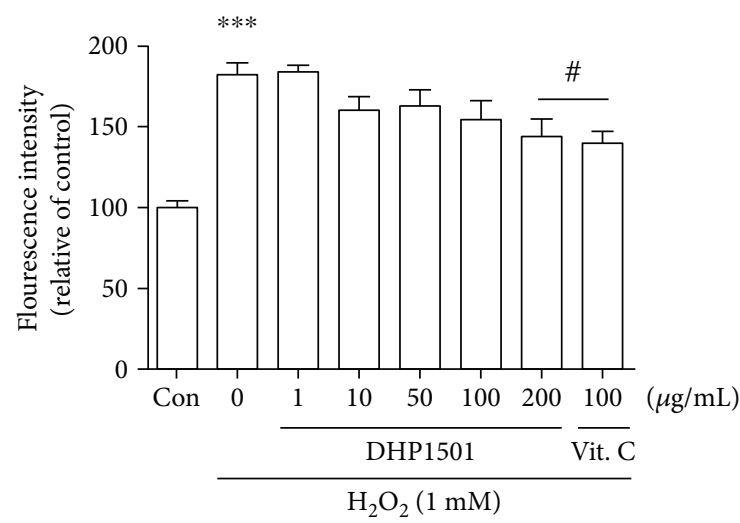

(a)

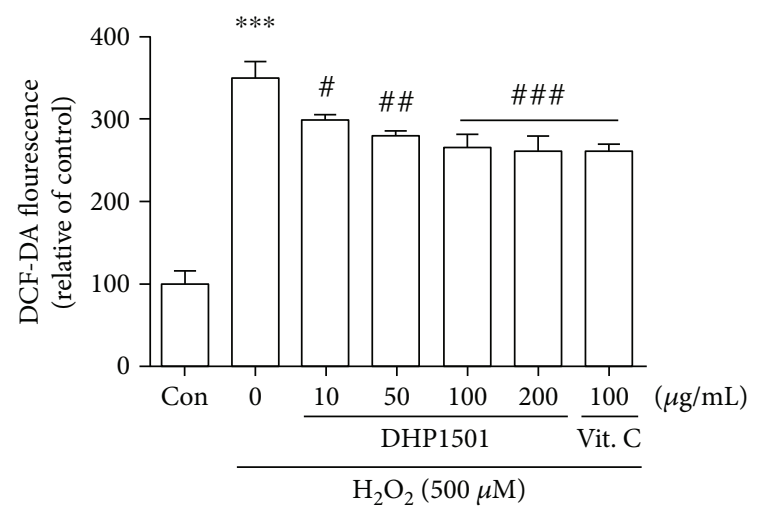

(b)

FIgURE 7: Antioxidant activity of DHP1501 through ROS measurement. (a) Fluorescence signal intensity (CellROX). (b) Fluorescence signal intensity (DCF-DA). Values were expressed as mean $\pm \mathrm{SD}(n=5-6 /$ group $)\left({ }^{* * *} p<0.05\right.$, versus the vehicle-treated control group; \#/\#\#/\#\#\# $p<0.05 / p<0.01 / p<0.001$, versus the vehicle-treated $\mathrm{H}_{2} \mathrm{O}_{2}$ group).

decreased them after 2 weeks compared with SHR. Especially, 400 or $600 \mathrm{mg} / \mathrm{kg}$ of DHP1501 had no significant difference with SBP and DBP compared to the SHR-captopril group at 4 weeks (Figures 9(a) and 9(b)).

Similarly, SBP and DBP measured by an invasive method at the end of the experiment were significantly higher in the SHR compared to the WKY $(121.3 \pm 7.4$ versus $202.2 \pm 11.2 \mathrm{mmHg}$ in SBP and $94.9 \pm 6.5$ versus 155.4 $\pm 7.6 \mathrm{mmHg}$ in DBP). SBP and DBP were significantly decreased in SHR-captopril compared with SHR $(137.9 \pm 9.3$ and $114.3 \pm 9.1 \mathrm{mmHg}$, respectively) and reduced in a dosedependent manner in SHR-DHP1501 $200(154.9 \pm 8.6$ and $133.2 \pm 9.4 \mathrm{mmHg})$, SHR-DHP1501 $400(146.1 \pm 10.2$ and $124.7 \pm 7.7 \mathrm{mmHg})$, and SHR-DHP1501 $600(142.1 \pm 9.6$ and $121.4 \pm 6.3 \mathrm{mmHg}$ ). The decrease in SBP and DBP as induced by DHP 1501 was statistically significant compared with the SHR (SBP: $F_{5,54}=84.72$; DBP: $F_{5,54}=65.21$ ) (Figure 9(c)).

3.9. Effects of DHP1501 on Renin and ACE Inhibitory Activity. The serum renin concentration was remarkably 


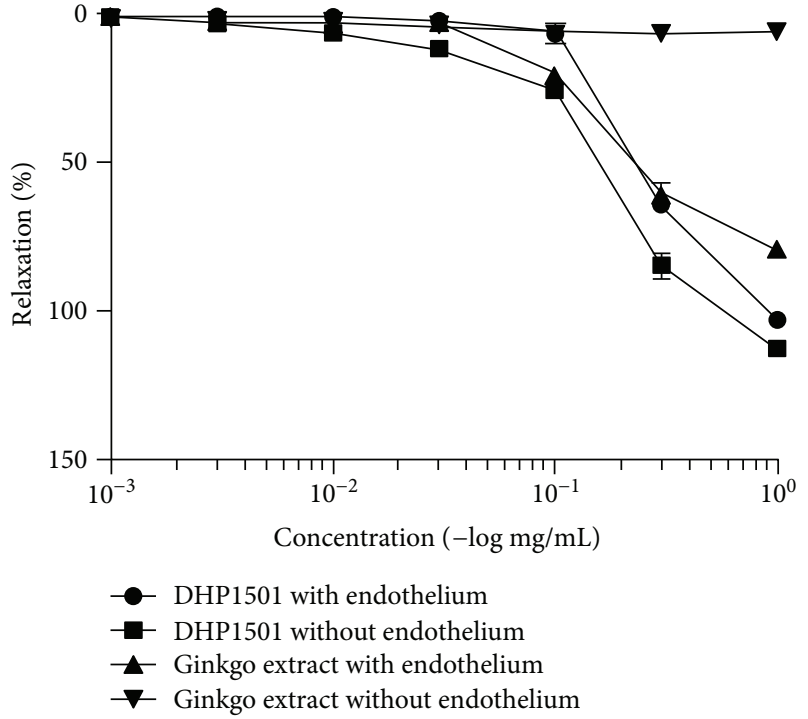

FIGURE 8: Effects of DHP1501 on relaxation in porcine coronary artery rings. Rings were contracted with U46619. Values were expressed as the mean \pm SD in terms of percentage relaxation of the contraction to U46619 ( $n=5$ /group). Relaxation induced by DHP1501 in intact rings or endothelium free rings. Values were expressed as mean \pm SD.

decreased in SHR compared with WKY $(1.34 \pm 0.18$ versus $3.48 \pm 0.63 \mathrm{ng} / \mathrm{mL}$, resp.). Note, however, that the DHP1501treated group had significantly lower serum renin concentration compared with the SHR group. The SHR-captopril group recorded a conspicuous increase $(4.46 \pm 0.21 \mathrm{ng} / \mathrm{mL})$. Similar to captopril used as a positive control, DHP1501 increased the serum renin concentrations $-2.78 \pm 0.42,2.85 \pm 0.47$, or $3.19 \pm 0.41-$ in SHR-DHP1501 200, SHR-DHP1501 400, or SHR-DHP1501 600, respectively, in a dose-dependent manner (Figure 10(a)). Contrary to serum renin, the serum ACE concentration was significantly increased in SHR compared with WKY $(21.57 \pm 3.03$ versus $15.81 \pm 2.12 \mathrm{ng} / \mathrm{mL}$, resp.). On the other hand, in terms of serum ACE concentration, significant group effects were observed in the DHP1501administered group $\left(\mathrm{F}_{5,54}=7.616\right)$. Specifically, serum ACE concentration was $18.92 \pm 1.26,18.76 \pm 2.12,18.66 \pm 2.10$, or $18.05 \pm 1.63 \mathrm{ng} / \mathrm{mL}$ in SHR-captopril, SHR-DHP1501 200, SHR-DHP1501 400, or SHR-DHP1501 600, respectively (Figure 10(b)).

\section{Discussion}

The endothelium forming the interior surface of blood vessels is involved in the regulation of vascular tone by releasing several mediators and maintaining balance between vasoconstriction and vasorelaxation [36]. Especially, the NO generated by endothelial nitric oxide synthase (eNOS) in endothelial cells mediates vascular relaxation and controls cardiovascular homeostasis $[37,38]$. In the vascular system, $\mathrm{NO}$ binds to $\mathrm{Fe}^{2+}$ heme of soluble guanylyl cyclase (sGC) and activates sGC, resulting in the production of cyclic guanosine- $3^{\prime}, 5^{\prime}$-monophosphate (cGMP). As the second messenger, cGMP activates protein kinase $G$ as well as the signaling cascade, such as $\mathrm{K}^{+}$channels. The activation of $\mathrm{K}^{+}$ channels hyperpolarizes the cell membrane and blocks $\mathrm{Ca}^{2+}$ channels, leading to vascular relaxation [39].

ROSs including superoxide $\left(\mathrm{O}_{2^{-}}\right)$react with the $\mathrm{NO}$ produced by eNOS and yield unstable molecules such as peroxynitrite (ONOO-) and peroxynitrous acid (HNO3), impairing endothelium-mediated vasorelaxation [40, 41]. Thus, antioxidants are reported to be beneficial in preventing endothelial dysfunction by scavenging superoxide and peroxynitrite [42]. Acanthopanax sessiliflorus fruit, which is colored berry, contains phytochemicals such as anthocyanin, total polyphenol, and total flavonoid, contributing to the antioxidant activity with health protection ability [43]. Many medicinal plants also reportedly contain a lot of antioxidants such as polyphenol; thus, the antioxidant activity of the extracts from natural resources is closely correlated with their total phenolic compounds possessing one or more aromatic rings with one or more hydroxyl groups [43-45]. In this present study, DHP1501 showed the electron passaging properties by scavenging $\mathrm{DPPH}$, ABTS, and peroxyl radicals (Figure 6) and showed biologically relevant antioxidant activity in CellROX and DCF-DA assays (Figure 7). Moreover, the dosages of DHP1501 which did not cause cytotoxicity in the vascular endothelial cells significantly facilitated the endothelial NO production (Figures 4 and 5). Decreased NO levels are associated with impaired endothelium-dependent vasodilation in many cardiovascular diseases, whereas increase in endothelialdependent NO release is considered to be beneficial to the cardiovascular system by improving vasodilation and blood circulation [46, 47]. Vasorelaxation is correlated with hypertension because structural and functional changes in the vascular endothelium contribute to hypertension [48]. Our study showed that DHP1501 possessed strong potential to induce full relaxation in the contracted vessels. In the endothelial-intact porcine coronary rings, vasorelaxation induced by DHP1501 was similar to that of the Ginkgo biloba leaf extract, which is proven to possess definite dose-dependent antihypertensive activity [49]. Additionally, DHP1501 exhibited effective vasorelaxation in the endothelium-free rings unlike the Ginkgo biloba leaf extract (Figure 8).

The antihypertensive effects of DHP1501 were definitively confirmed in SHRs, which have been widely used to investigate the antihypertensive effects of natural products or foods [50]. Following oral administration of various concentrations of DHP1501 or captopril, SBP and DBP significantly decreased. Especially, a high dose of DHP1501 $(600 \mathrm{mg} / \mathrm{kg})$ decreased blood pressure to levels comparable to the captopril-administered group (Figures 9(a) and 9(b)).

The renin-angiotensin-aldosterone system (RAAS) plays a crucial role in regulating blood pressure in the body [51]. Generally, renin activates RAAS by cleaving angiotensinogen and yields angiotensin I, which is further converted into angiotensin II, a potent vasoconstrictor. Eventually, renin causes an increase in blood pressure. Thus, elevated renin levels in SHR, which is an established model of essential hypertension, have been reported in several studies [52-54]. Still, there is controversy on the renin level in SHR because 


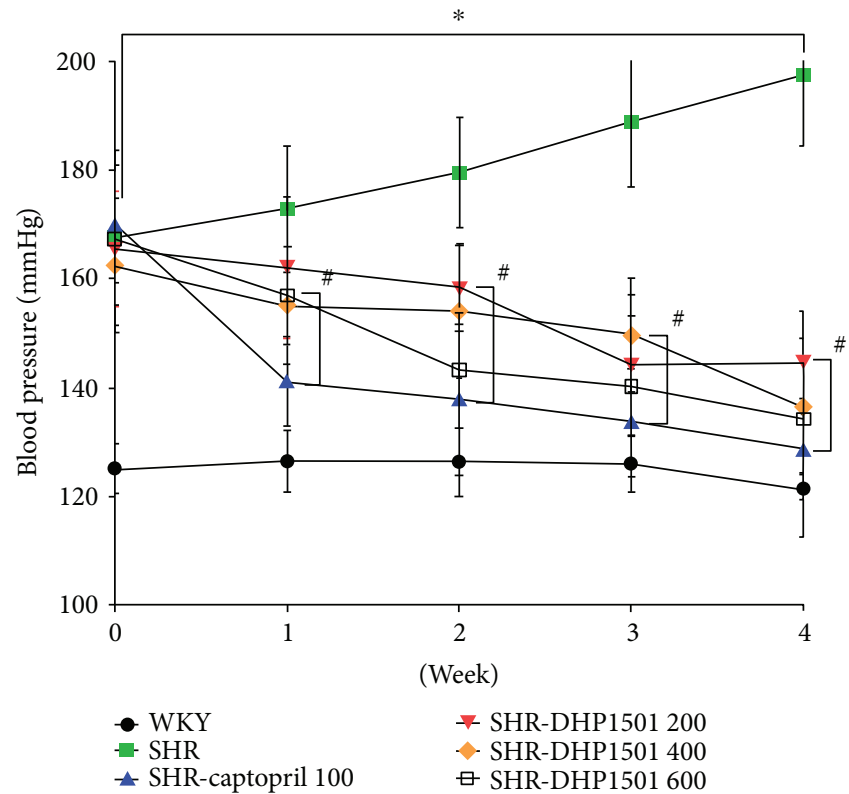

(a)

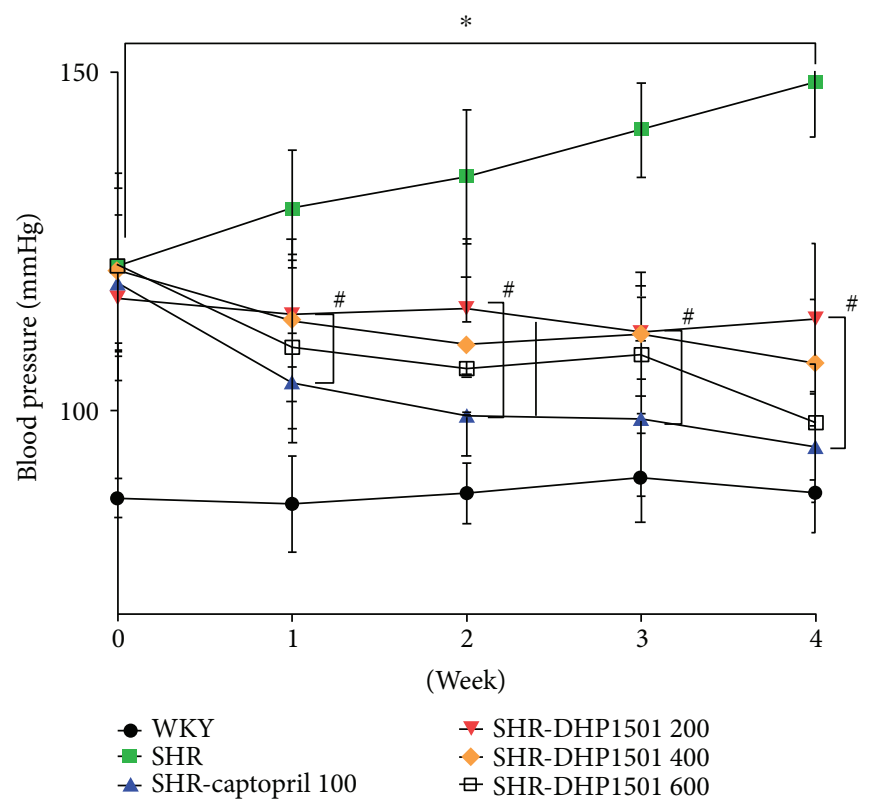

(b)

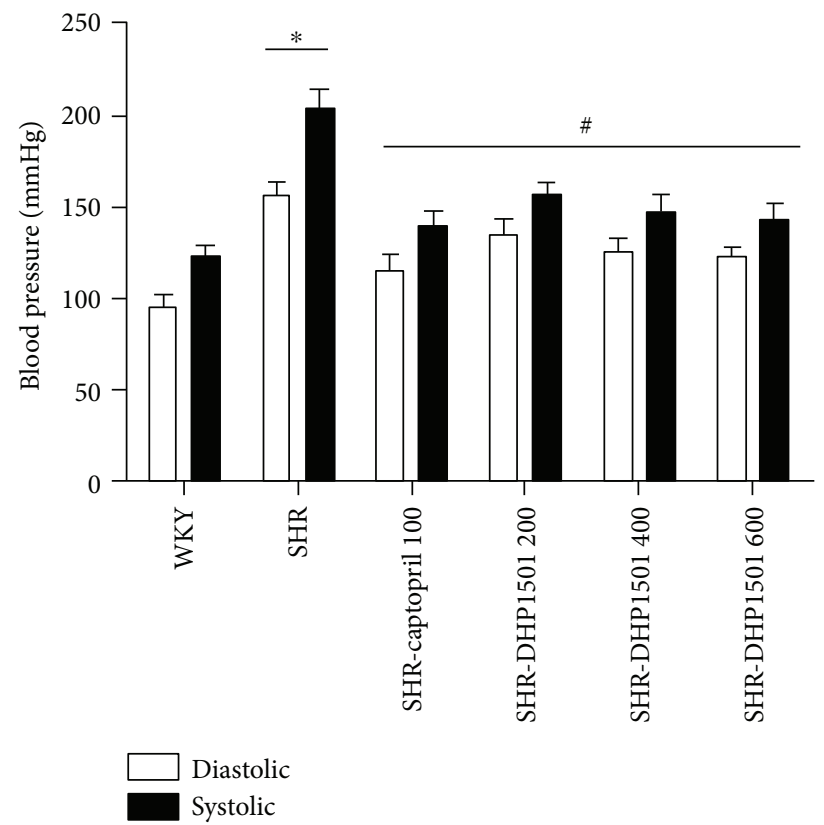

(c)

Figure 9: Effects of DHP1501 on blood pressure; SBP and DBP. (a) Changes in SBP and DBP induced by DHP1501 for 4 weeks. (b) Changes in SBP and DBP induced by DHP1501 at the end of the experiment period. Groups included the following: WKYs as normal control; SHR (saline as the vehicle); SHR-captopril 100 (a 4-week daily course of oral captopril at a dose of $100 \mathrm{mg} / \mathrm{kg}$ ); SHR-DHP1501 200 (a 4-week daily course of oral DHP1501 at a dose of $200 \mathrm{mg} / \mathrm{kg}$ ); SHR-DHP1501 400 (a 4-week daily course of oral DHP1501 at a dose of $400 \mathrm{mg} /$ $\mathrm{kg}$ ); and SHR-DHP1501 600 (a 4-week daily course of oral DHP1501 at a dose of $600 \mathrm{mg} / \mathrm{kg}$ ). (c) Effect of DHP1501 on SBP and DBP measured by an invasive method. Values were expressed as the mean $\pm \mathrm{SD}$ ( $n=10$ /group) $\left({ }^{*} p<0.05\right.$, versus the WKY group; ${ }^{\#} p<0.05$, versus the SHR group).

other studies have reported normal or subnormal levels of renin in SHR compared with a normotensive Wistar rat $[55,56]$. Sen et al. [57] also showed that plasma renin activity was significantly higher in SHR at an early age, decreasing with the development of stable hypertension and finally becoming lower than normal in established hypertension.
They suggested that renin may play a primary role along with other possible factors in the pathology of hypertension. Recently, $\mathrm{Qu}$ et al. reported that the renin content in the SHR groups was lower than that in the age-matched WKY rats, and similar trends were found in the human plasma. They also stated that renin levels were negatively correlated 


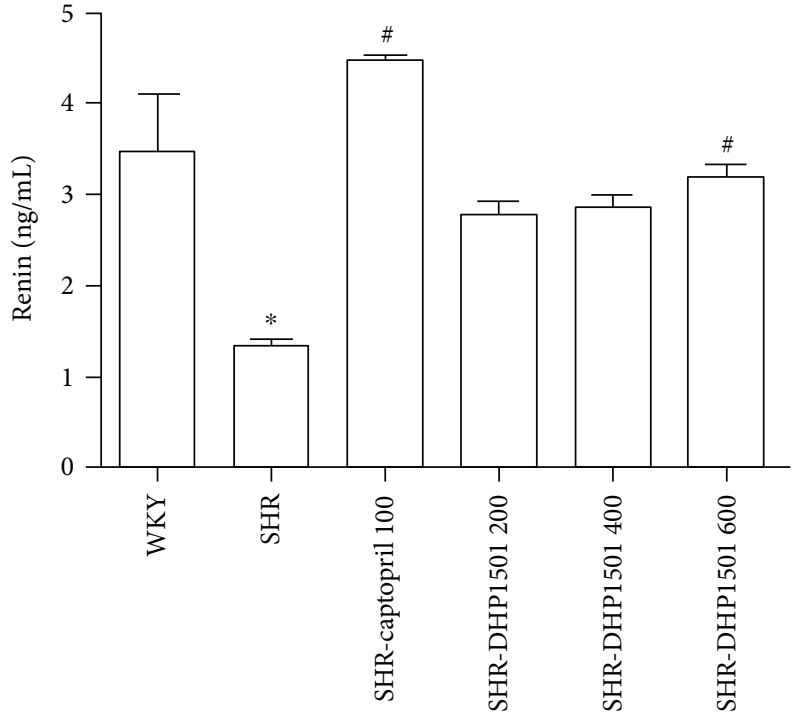

(a)

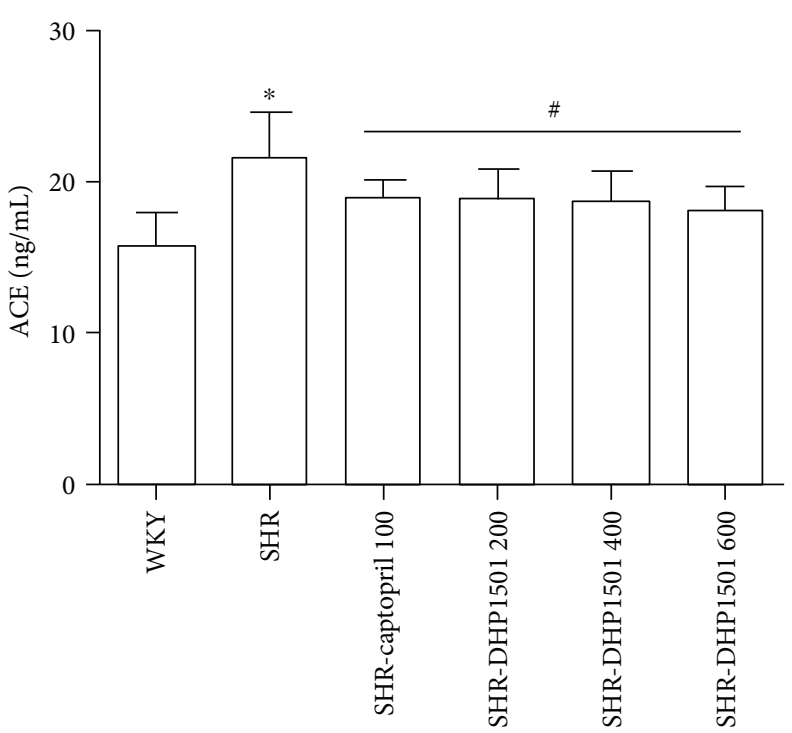

(b)

FIGURE 10: Effects of DHP1501 on serum renin (a) and ACE concentrations (b). (a) Changes in renin concentration induced by DHP1501. (b) Changes in ACE concentration induced by DHP1501. Groups included the following: WKYs as normal control; SHR (saline as the vehicle); SHR-captopril 100 (a 4-week daily course of oral captopril at a dose of $100 \mathrm{mg} / \mathrm{kg}$ ); SHR-DHP1501 200 (a 4-week daily course of oral DHP1501 at a dose of $200 \mathrm{mg} / \mathrm{kg}$ ); SHR-DHP1501 400 (a 4-week daily course of oral DHP1501 at a dose of $400 \mathrm{mg} / \mathrm{kg}$ ); and SHRDHP1501 600 (a 4-week daily course of oral DHP1501 at a dose of $600 \mathrm{mg} / \mathrm{kg}$ ). Values were expressed as the mean \pm SD ( $n=10 /$ group) $\left({ }^{*} p<0.05\right.$, versus the WKY group; ${ }^{\#} p<0.05$, versus the SHR group).

with blood pressure [58]. In this study, too, serum renin concentration in SHR was conspicuously lower than that in WKY, although SBP and DBP were significantly higher in SHR than WKY. On the other hand, captopril and DHP1501 significantly increased serum renin concentration in SHR (Figure 9). According to Bolterman et al., captopril, an ACE inhibitor, effectively treated high blood pressure even as levels of plasma renin activity in the SHR are normal, thus suggesting that angiotensin II plays a major role in the etiology of hypertension in SHR. Finally, they concluded that captopril may decrease blood pressure in SHR by selectively decreasing angiotensin II, oxidant stress, and endothelium involved in the increase of blood pressure [59]. Similar to captopril, DHP1501 reduced the serum ACE in SHRs (Figure 9(b)) in a dose-dependent, significant manner. Our previous study also reported that DHP1501 decreased ACE activity in HUVECs [31]. In RAAS, ACE converts angiotensin I into angiotensin II, which is considered a potent vasoconstrictor, and degrades bradykinin-a potent endothelium-dependent vasodilator-by releasing prostacyclin, NO, and endothelium-derived hyperpolarizing factor [60-62]. Therefore, the inhibition of ACE has been extensively used as a therapeutic strategy for the prevention and treatment of hypertension and has been found to improve endothelium-dependent vasorelaxation $[6,48]$. As a followup study, we will evaluate the unexpected side effects of DHP1501 at WKY rats.

\section{Conclusions}

Overall, we investigated the antihypertensive effect of DHP1501, which may be attributed to various factors such as free radical scavenging capacity, facilitation of NO production, and ACE inhibition, resulting in the improvement of vascular relaxation and decrease in blood pressure in the hypertensive animal model. These results suggest that DHP1501 may be a promising functional material for the prevention and treatment of hypertension. The advantages of hybrid Q-TOF mass spectrometry include not only quality detection capability and sensitivity but also accurate measurement and reliable chemical fragmentation, making the structure elucidations easier. It can be used for qualitative and quantitative determination of active compounds, which is helpful in improving the quality control of ethanolic extract from A. sessiliflorus fruits and its pharmaceutical preparations.

\section{Abbreviations}

ACE: $\quad$ Angiotensin-converting enzyme

ABTS: $\quad 2,2^{\prime}$-Azino-di-(3-ethylbenzthiazoline sulfonic acid)

Ab: $\quad$ Absorbance

ANOVA: One-way analysis of variance

AUC: $\quad$ Areas under the fluorescence decay curve

cGMP: $\quad$ Cyclic guanosine- $3^{\prime}, 5^{\prime}$-monophosphate

DAF-FM/DA: 4-Amino-5-methylamino- $2^{\prime}, 7^{\prime}$-difluorofluorescein diacetate

DBP: $\quad$ Diastolic blood pressure

DHP1501: The ethanolic extract of A. sesssilflorus

DPPH: 2,2-diphenyl-1-picrylhydrazyl

eNOS: $\quad$ Endothelial nitric oxide synthase

HUVECs: Human umblical vein endothelial cells 


$\begin{array}{ll}\text { IRB: } & \text { Institutional review board } \\ \text { KAMSI: } & \text { Korea Animal Medical Science Institute } \\ \text { LOD: } & \text { Limit of detection } \\ \text { LOQ: } & \text { Limit of quantification } \\ \text { NO: } & \text { Nitric oxide } \\ \text { ORAC: } & \text { Oxygen radical absorption capacity } \\ \text { RAAS: } & \text { Renin-angiotensin-aldosterone system } \\ \text { REN: } & \text { Renin } \\ \text { Rt: } & \text { Retention time } \\ \text { SBP: } & \text { Systolic blood pressure } \\ \text { SD: } & \text { Standard deviation } \\ \text { sGC: } & \text { Soluble guanylyl cyclase } \\ \text { SHRs: } & \text { Spontaneous hypertensive rats } \\ \text { TE: } & \text { Trolox equivalents } \\ \text { TIC: } & \text { Total ion chromatogram } \\ \text { Trolox: } & \text { 6-Hydroxy-2,5,7,8-tetramethylchroman-2- } \\ & \text { carboxylic acid } \\ \text { WKY: } & \text { Wistar-Kyoto rats. }\end{array}$

\section{Disclosure}

The founding sponsors had no role in the design of the study; collection, analyses, or interpretation of the data; writing of the manuscript; or decision to publish the results.

\section{Conflicts of Interest}

The authors declare no conflicts of interest.

\section{Authors' Contributions}

Dae Young Lee and In Ho Jung conceived and designed the experiments. In Ho Jung and Dae Hyun Kim performed the animal experiments. Yeong-Geun Lee isolated the compounds. Dae Young Lee elucidated the structures and performed the NMRs and mass spectrometry of the compounds. Geum-Soog Kim contributed to the plant material preparation. Sung Eun Kim and Haneul Kim carried out the biological assay (in vivo) and helped with the preparation of the manuscript. Dae Young Lee wrote the paper, and Nam-In Baek managed the research project. All authors helped in preparing the paper and approved the final version.

\section{Acknowledgments}

This work was conducted with the support of the "Cooperative Research Program for Agriculture Science \& Technology Development" (Project no. PJ01133301), Rural Development Administration, Republic of Korea.

\section{References}

[1] T. M. Abegaz, A. Shehab, E. A. Gebreyohannes, A. S. Bhagavathula, and A. A. Elnour, "Nonadherence to antihypertensive drugs: a systematic review and meta-analysis," Medicine, vol. 96, no. 4, article e5641, 2017.

[2] S. S. Lim, T. Vos, A. D. Flaxman et al., "A comparative risk assessment of burden of disease and injury attributable to 67 risk factors and risk factor clusters in 21 regions, 1990-2010: a systematic analysis for the global burden of disease study 2010," The Lancet, vol. 380, no. 9859, pp. 2224-2260, 2012.

[3] J. J. Guilbert, "The world health report 2002 - reducing risks, promoting healthy life," Education for Health: Change in Learning \& Practice, vol. 16, no. 2, p. 230, 2003.

[4] R. Shi, K. Liu, D. Shi, Q. Liu, and X. Chen, "Effects of amlodipine and valsartan on blood pressure variability and pulse wave velocity in hypertensive patients," The American Journal of the Medical Sciences, vol. 353, no. 1, pp. 6-11, 2017.

[5] S. K. Pal and Y. Shukla, "Herbal medicine: current status and the future," Asian Pacific Journal of Cancer Prevention, vol. 4, pp. 281-299, 2003.

[6] T. Niaz, Z. Hafeez, and M. Imran, "Prospectives of antihypertensive nano-ceuticals as alternative therapeutics," Current Drug Targets, vol. 18, no. 11, pp. 1269-1280, 2017.

[7] I. H. Page, "The mosaic theory 32 years later," Hypertension, vol. 4, no. 2, p. 177, 1982.

[8] K. A. Hom, R. Hirsch, and R. G. Elluru, "Antihypertensive drug-induced angioedema causing upper airway obstruction in children," International Journal of Pediatric Otorhinolaryngology, vol. 76, no. 1, pp. 14-19, 2012.

[9] G. Shapovalov, R. Skryma, and N. Prevarskaya, "Calcium channels and prostate cancer," Recent Patents on AntiCancer Drug Discovery, vol. 8, no. 1, pp. 18-26, 2013.

[10] R. M. Kumbhare, U. B. Kosurkar, P. K. Bagul et al., "Synthesis and evaluation of novel triazoles and mannich bases functionalized 1,4-dihydropyridine as angiotensin converting enzyme (ACE) inhibitors," Bioorganic \& Medicinal Chemistry, vol. 22, no. 21, pp. 5824-5830, 2014.

[11] E. Özkaya and K. D. Yazganoglu, Adverse Cutaneous Drug Reactions to Cardiovascular Drugs, Springer, London, 2014.

[12] K. S. Oh, S. Y. Ryu, B. K. Oh, H. W. Seo, Y. S. Kim, and B. H. Lee, "Antihypertensive, vasorelaxant, and antioxidant effect of root bark of Ulmus macrocarpa," Biological and Pharmaceutical Bulletin, vol. 31, no. 11, pp. 2090-2096, 2008.

[13] P. Prahalathan, S. Kumar, and B. Raja, "Effect of morin, a flavonoid against DOCA-salt hypertensive rats: a dose dependent study," Asian Pacific Journal of Tropical Biomedicine, vol. 2, no. 6, pp. 443-448, 2012.

[14] S. A. Adefegha, S. I. Oyeleye, and G. Oboh, "Distribution of phenolic contents, antidiabetic potentials, antihypertensive properties, and antioxidative effects of Soursop (Annona muricata L.) fruit parts in vitro," Biochemistry Research International, vol. 2015, Article ID 347673, 8 pages, 2015.

[15] E. L. Schiffrin, "Antioxidants in hypertension and cardiovascular disease," Molecular Interventions, vol. 10, no. 6, pp. 354-362, 2010.

[16] N. Sinha and P. Dabla, "Oxidative stress and antioxidants in hypertension-a current review," Current Hypertension Reviews, vol. 11, no. 2, pp. 132-142, 2015.

[17] D. Burger and R. M. Touyz, "Cellular biomarkers of endothelial health: microparticles, endothelial progenitor cells, and circulating endothelial cells," Journal of the American Society of Hypertension, vol. 6, no. 2, pp. 85-99, 2012.

[18] R. Rodrigo, H. Prat, W. Passalacqua, J. Araya, C. Guichard, and J. P. Bächler, "Relationship between oxidative stress and essential hypertension," Hypertension Research, vol. 30, no. 12, pp. 1159-1167, 2007.

[19] R. M. Touyz and E. L. Schiffrin, "Increased generation of superoxide by angiotensin II in smooth muscle cells from resistance arteries of hypertensive patients: role of phospholipase 
D-dependent NAD(P)H oxidase-sensitive pathways," Journal of Hypertension, vol. 19, no. 7, pp. 1245-1254, 2001.

[20] E. Y. Kim, I. H. Baik, J. H. Kim, S. R. Kim, and M. R. Rhyu, "Screening of the antioxidant activity of some medicinal plants," Korean Journal of Food Science and Technology, vol. 36, no. 2, pp. 333-338, 2004.

[21] D. Y. Lee, K. H. Seo, R. H. Jeong et al., “Anti-inflammatory lignans from the fruits of Acanthopanax sessiliflorus," Molecules, vol. 18, no. 1, pp. 41-49, 2012.

[22] B. S. Jung and M. K. Shin, Hyang Yak Dae Sa Jeon, vol. 3, Young Lim Sa, Seoul, Korea, 2003.

[23] L. Song, Y. Wu, L. Hu et al., Zhong Hua Ben Cao 22, vol. 5, Shanghai Scientific Technologic, Shanghai, China, 1999.

[24] S. Yang, Y. Chun-Juan, Y. U. Kai, and L. I. Fa-Mei, "In vivo antithrombotic and antiplatelet activities of a quantified Acanthopanax sessiliflorus fruit extract," Chinese Journal of Natural Medicines, vol. 9, no. 2, pp. 141-145, 2011.

[25] D. A. Vorchheimer and R. Becker, "Platelets in atherothrombosis," Mayo Clinic Proceedings, vol. 81, no. 1, pp. 59-68, 2006.

[26] D. Tousoulis, I. P. Paroutoglou, N. Papageorgiou, M. Charakida, and C. Stefanadis, "Recent therapeutic approaches to platelet activation in coronary artery disease," Pharmacology \& Therapeutics, vol. 127, no. 2, pp. 108-120, 2010.

[27] G. Vilahur and L. Badimon, "Antiplatelet properties of natural products,” Vascular Pharmacology, vol. 59, no. 3-4, pp. 67-75, 2013.

[28] S. J. In, D. Y. Lee, K. H. Seo et al., "Anti-oxidant activity of phenolic compound isolated from the fruits of Acanthopanax sessiliflorus Seeman," Journal of Applied Biological Chemistry, vol. 55, no. 4, pp. 217-220, 2012.

[29] D. Y. Lee, K. H. Seo, D. S. Lee et al., "Bioactive 3,4-seco-triterpenoids from the fruits of Acanthopanax sessiliflorus," Journal of Natural Products, vol. 75, no. 6, pp. 1138-1144, 2012.

[30] H. S. Ryoo, S. Y. Park, S. Y. Chang, and C. S. Yook, “Triterpene components from the leave of Acanthopanax sessiliflorus Seem," Korean Journal of Pharmacognosy, vol. 34, no. 4, pp. 269-273, 2003.

[31] J. W. Lee, N. I. Baek, and D. Y. Lee, "Inhibitory effects of secotriterpenoids from Acanthopanax sessiliflorus fruits on HUVEC invasion and ACE activity," Natural Product Communications, vol. 10, no. 9, pp. 1517-1520, 2015.

[32] D. Lee, H.-G. Kim, Y.-G. Lee et al., "Isolation and quantification of ginsenoside Rh23, a new anti-melanogenic compound from the leaves of Panax ginseng," Molecules, vol. 23, no. 2, p. 267, 2018.

[33] N. J. Miller, C. Rice-Evans, and M. J. Davies, "A new method for measuring antioxidant activity," Biochemical Society Transactions, vol. 21, no. 2, p. 95S, 1993.

[34] S. G. Nam, C. S. Yook, I. S. Kim, H. S. Choi, and S. Y. Park, "Studies on the constituents of the leaves of Acanthopanax divaricatus forma flavi-flos," Natural Product Sciences, vol. 12, no. 3, pp. 119-121, 2006.

[35] K. Shirasuna, M. Miyakoshi, S. Mimoto et al., "Lupane triterpenoid glycosyl esters from leaves of Acanthopanax divaricatus," Phytochemistry, vol. 45, no. 3, pp. 579-584, 1997.

[36] P. Balakumar and G. Taneja, "Fish oil and vascular endothelial protection: bench to bedside," Free Radical Biology \& Medicine, vol. 53, no. 2, pp. 271-279, 2012.
[37] H. Y. Kim, H. Oh, X. Li, K. W. Cho, D. G. Kang, and H. S. Lee, "Ethanol extract of seeds of Oenothera odorata induces vasorelaxation via endothelium-dependent NO-cGMP signaling through activation of Akt-eNOS-sGC pathway," Journal of Ethnopharmacology, vol. 133, no. 2, pp. 315323, 2011.

[38] H. Y. Son, H. W. Jung, W. K. Kim, and Y. K. Park, “The vasoprotective effect of JP05 through the activation of PI3K/Aktdependent eNOS and MEK/ERK pathways in brain endothelial cells," Journal of Ethnopharmacology, vol. 130, no. 3, pp. 607-613, 2010.

[39] B. R. Silva, T. D. Paula, M. Paulo, and L. M. Bendhack, "Nitric oxide signaling and the cross talk with prostanoids pathways in vascular system," Journal of Medicinal Chemistry, vol. 13, no. 4, pp. 319-333, 2017.

[40] M. Akhlaghi and B. Bandy, "Mechanisms of flavonoid protection against myocardial ischemia-reperfusion injury," Journal of Molecular and Cellular Cardiology, vol. 46, no. 3, pp. 309317, 2009.

[41] S. Benito, D. Lopez, M. P. Sáiz et al., "A flavonoid-rich diet increases nitric oxide production in rat aorta," British Journal of Pharmacology, vol. 135, no. 4, pp. 910-916, 2002.

[42] N. Kang, J. H. Lee, W. Lee et al., "Gallic acid isolated from Spirogyra sp. improves cardiovascular disease through a vasorelaxant and antihypertensive effect," Environmental Toxicology and Pharmacology, vol. 39, no. 2, pp. 764-772, 2015.

[43] L. Chen, X. Xin, Q. Yuan, D. Su, and W. Liu, "Phytochemical properties and antioxidant capacities of various colored berries," Journal of the Science of Food and Agriculture, vol. 94, no. 2, pp. 180-188, 2014.

[44] A. A. Adedapo, F. O. Jimoh, A. J. Afolayan, and P. J. Masika, "Antioxidant properties of the methanol extracts of the leaves and stems of Celtis africana," Records of Natural Products, vol. 3, no. 1, pp. 23-31, 2009.

[45] M. Cho, H. S. Lee, I. J. Kang, M. H. Won, and S. You, “Antioxidant properties of extract and fractions from Enteromorpha prolifera, a type of green seaweed," Food Chemistry, vol. 127, no. 3, pp. 999-1006, 2011.

[46] W. L. Chen, Y. Qian, W. F. Meng et al., "A novel marine compound xyloketal B protects against oxidized LDL-induced cell injury in vitro," Biochemical Pharmacology, vol. 78, no. 8, pp. 941-950, 2009.

[47] H. M. Hügel, N. Jackson, B. May, A. L. Zhang, and C. C. Xue, "Polyphenol protection and treatment of hypertension," Phytomedicine, vol. 23, no. 2, pp. 220-231, 2016.

[48] M. Clozel, H. Kuhn, and F. Hefti, "Effects of angiotensin converting enzyme inhibitors and of hydralazine on endothelial function in hypertensive rats," Hypertension, vol. 16, no. 5, pp. 532-540, 1990.

[49] S. M. Mansour, A. K. Bahgat, A. S. El-Khatib, and M. T. Khayyal, "Ginkgo biloba extract (EGb 761) normalizes hypertension in $2 \mathrm{~K}, 1 \mathrm{C}$ hypertensive rats: role of antioxidant mechanisms, ACE inhibiting activity and improvement of endothelial dysfunction," Phytomedicine, vol. 18, no. 8-9, pp. 641-647, 2011.

[50] W. C. Dornas and M. E. Silva, "Animal models for the study of arterial hypertension,” Journal of Biosciences, vol. 36, no. 4, pp. 731-737, 2011.

[51] W. S. Ryu, S. W. Kim, and C. J. Kim, "Overview of the reninangiotensin system," Korean Circulation Journal, vol. 37, no. 3, pp. 91-96, 2007. 
[52] J. Gao, E. K. Kerut, F. Smart et al., "Sympathoinhibitory effect of radiofrequency renal denervation in spontaneously hypertensive rats with established hypertension," American Journal of Hypertension, vol. 29, no. 12, pp. 1394-1401, 2016.

[53] V. da Silva Cristino, G. F. Cordeiro, C. A. de Bemda et al., "Euterpe oleracea Mart. seed extract protects against renal injury in diabetic and spontaneously hypertensive rats: role of inflammation and oxidative stress," European Journal of Nutrition, vol. 57, no. 2, pp. 817-832, 2017.

[54] M. Naruse and T. Inagami, "Markedly elevated specific renin levels in the adrenal in genetically hypertensive rats," PNAS, vol. 79, no. 10, pp. 3295-3299, 1982.

[55] N. J. Samani, J. D. Swales, and W. J. Brammar, "A widespread abnormality of renin gene expression in the spontaneously hypertensive rat: modulation in some tissues with the development of hypertension," Clinical Science, vol. 77, no. 6, pp. 629636, 1989.

[56] A. Nakamura and E. J. Johns, "Renal nerves, renin, and angiotensinogen gene expression in spontaneously hypertensive rats," Hypertension, vol. 25, no. 4, pp. 581-586, 1995.

[57] S. Sen, R. R. Smeby, and F. M. Bumpus, "Renin in rats with spontaneous hypertension," Circulation Research, vol. 31, no. 6, pp. 876-880, 1972.

[58] Y. Y. Qu, J. Hui, L. M. Wang et al., "Reduced expression of the extracellular calcium-sensing receptor (CaSR) is associated with activation of the renin-angiotensin system (RAS) to promote vascular remodeling in the pathogenesis of essential hypertension," PLoS One, vol. 11, no. 7, article e0157456, 2016.

[59] R. J. Bolterman, M. C. Manriquez, M. C. Ortiz Ruiz, L. A. Juncos, and J. C. Romero, "Effects of captopril on the renin angiotensin system, oxidative stress, and endothelin in normal and hypertensive rats," Hypertension, vol. 46, no. 4, pp. 943947, 2005.

[60] J. Y. Je, J. Y. Park, W. K. Jung, P. J. Park, and S. K. Kim, "Isolation of angiotensin I converting enzyme (ACE) inhibitor from fermented oyster sauce, Crassostrea gigas," Food Chemistry, vol. 90, no. 4, pp. 809-814, 2005.

[61] D. Staljanssens, J. Van Camp, G. Herregods et al., “Antihypertensive effect of insect cells: in vitro and in vivo evaluation," Peptides, vol. 32, no. 3, pp. 526-530, 2011.

[62] N. Y. Yoon, K. B. Shim, C. W. Lim, and S. B. Kim, “Antioxidant and angiotensin I converting enzyme inhibitory activities of red snow crab Chionoecetes japonicas shell hydrolysate by enzymatic hydrolysis," Fisheries and Aquatic Sciences, vol. 16, no. 4, pp. 237-242, 2013. 


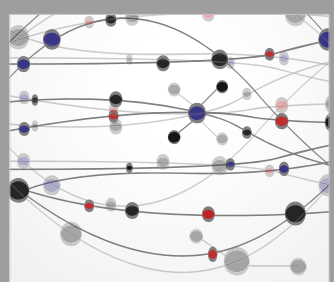

The Scientific World Journal
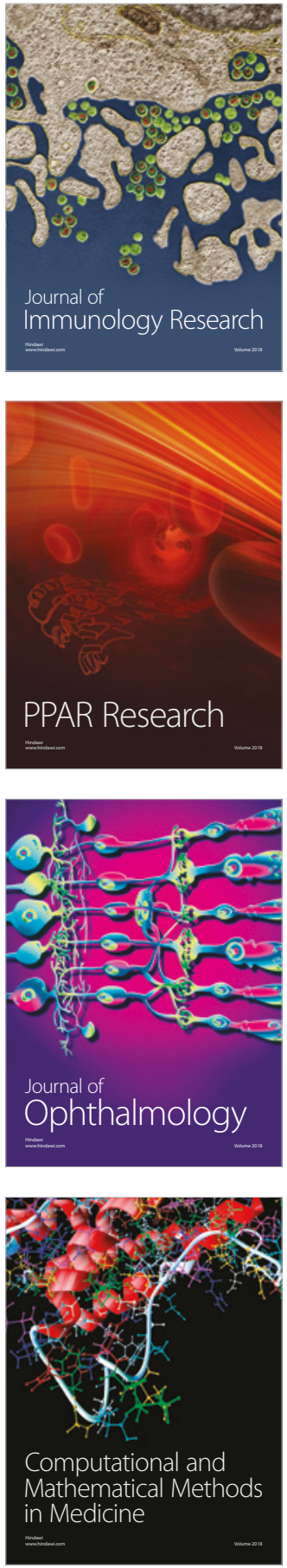

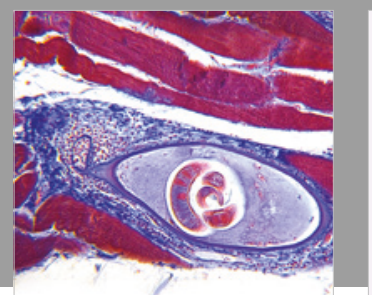

Gastroenterology Research and Practice

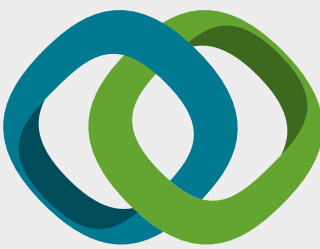

\section{Hindawi}

Submit your manuscripts at

www.hindawi.com
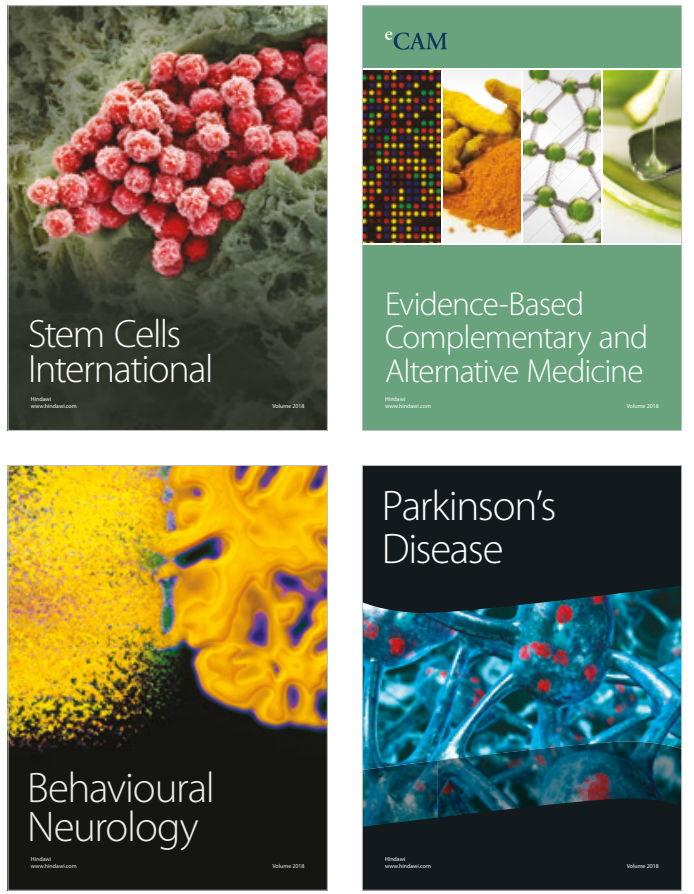

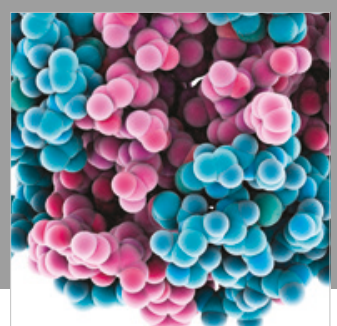

ournal of

Diabetes Research

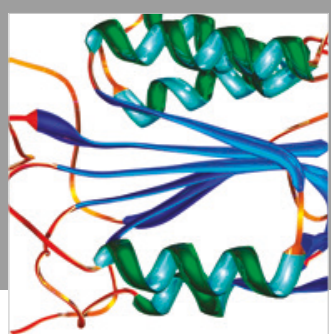

Disease Markers
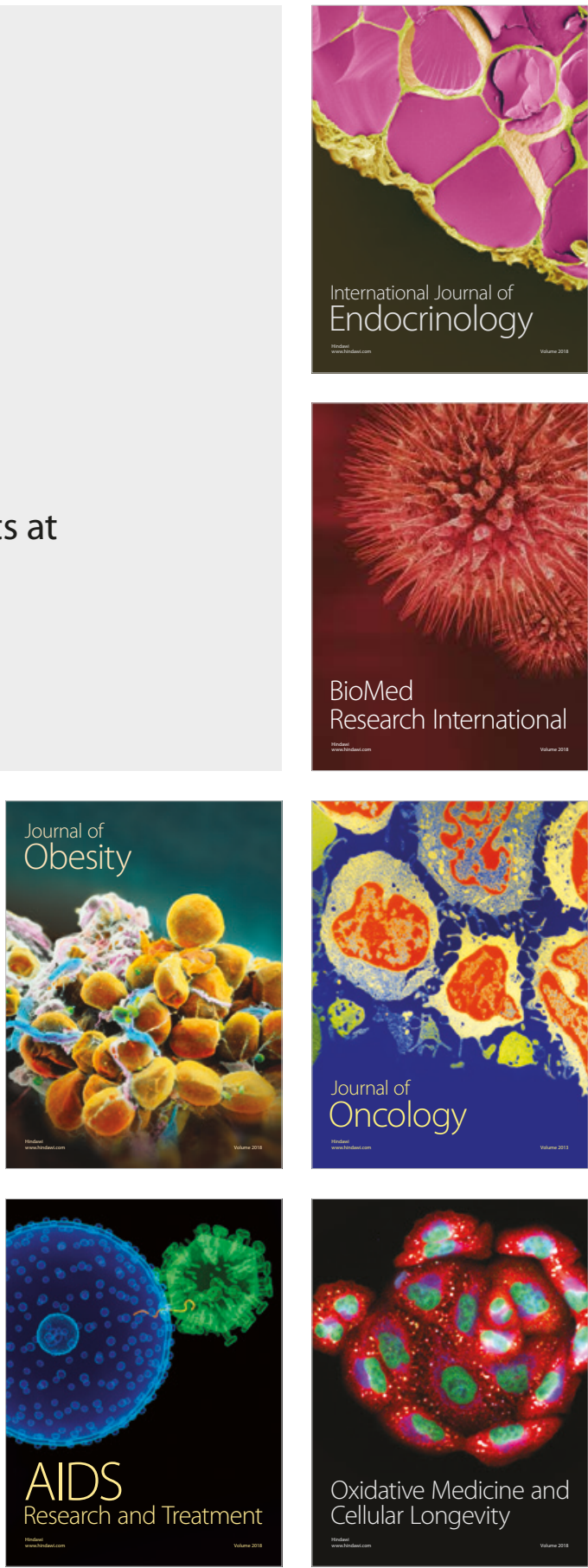